\title{
FATORES DE RISCO PARA MUCOSITE BUCAL EM PACIENTES COM LEUCEMIA LINFÓIDE AGUDA SUBMETIDOS A DIFERENTES PROTOCOLOS DE TRATAMENTO
}

\section{SUZANA LUZIA COELHO FIGLIOLIA}

Tese apresentada à Faculdade de Odontologia de Bauru da Universidade de São Paulo, como parte dos requisitos para obtenção do grau de Doutor em Odontologia, área de Patologia Bucal. 


\section{FATORES DE RISCO PARA MUCOSITE BUCAL EM PACIENTES COM LEUCEMIA LINFÓIDE AGUDA SUBMETIDOS A DIFERENTES PROTOCOLOS DE TRATAMENTO}

SUZANA LUZIA COELHO FIGLIOLIA

Tese apresentada à Faculdade de Odontologia de Bauru da Universidade de São Paulo, como parte dos requisitos para obtenção do grau de Doutor em Odontologia, área de Patologia Bucal.

Orientadora: Profa. Dra. Denise Tostes Oliveira

BAURU

2006 
Figliolia, Suzana Luzia Coelho

F468f Fatores de risco para mucosite bucal em pacientes com Leucemia Linfóide Aguda submetidos a diferentes protocolos de tratamento/ Suzana Luzia Coelho Figliolia.--Bauru, 2006.

xvi, 117p.: il.; $30 \mathrm{~cm}$

Tese. (Doutorado) - Faculdade de Odontologia de Bauru. Universidade de São Paulo.

Orientadora: Prof. ${ }^{a}$ Dr. ${ }^{a}$ Denise Tostes Oliveira

Autorizo, exclusivamente para fins acadêmico e científico, a reprodução total ou parcial, desta tese por processos fotocopiadores e/ou meios eletrônicos.

Assinatura da autora:

Data: Bauru, 7 de novembro de 2006.

Projeto de pesquisa aprovado pela Comissão de Ética Médica do Hospital Infantil Darcy Vargas - número 39/04, em reunião de 12 de outubro de 2004. 


\section{SUZANA LUZIA COELHO FIGLIOLIA}

3 de novembro de $1963 \quad$ Nascimento

Bauru - SP

Filiação

Luiz José Coelho

Thereza de Jesus Secco Coelho

1982-1985

Curso de Graduação em Odontologia pela Faculdade de Odontologia de Bauru - Universidade de São Paulo

$1999-2001$

Mestrado em Saúde Coletiva pela Faculdade de Odontologia de Bauru - Universidade de São Paulo

2003-2006

Doutorado em Patologia Bucal pela Faculdade de Odontologia de Bauru - Universidade de São Paulo

1990-Atual

Cirurgiã-dentista - Prefeitura Municipal de Bauru - SP. 
“O ideal da Educação não é ensinar o máximo, maximizar os resultados, mas é, acima de tudo, aprender a aprender, aprender a se desenvolver e aprender a continuar a se desenvolver"

Jean Piaget 


\title{
A DEUS PAI,
}

Por tornar tudo possível;

\author{
Aos meus pais LUIZ e THEREZA, \\ e avós OLAVO e HERONDINA,
}

que me ensinaram o sentido da vida;

Aos meus filhos PEDRO e AMANDA,

pelo carinho e grande amor que me dedicam;

Ao meu marido, JOSÉ MAURO,

pelo companheirismo e cumplicidade;

A SANDRA $P$ WALTER

\section{SUZETE e BENTO}

pelo sempre apoio e incentivo;

A minha sogra $\boldsymbol{E L} \boldsymbol{Y}$,

sempre torcendo pelas nossas conquistas;

\section{Muito Obrigada Sempre}


À Professora Doutora DENISE TOSTES OLIVEIRA, que sem medir esforços, não só me orientou como me ensinou com amizade e seriedade. Agradeço pela confiança e pelo estímulo presente durante todo o período de elaboração e realização deste trabalho. 


\section{AGRADECIMENTOS}

Aos docentes da Disciplina de Patologia da Faculdade de Odontologia de Bauru - USP, Prof. Dr. Alberto Consolaro, Prof $^{\mathrm{a}}$ Dr $^{\mathrm{a}}$ Denise Tostes Oliveira, Prof. Dr. Luís Antônio de Assis Taveira e $\operatorname{Prof}^{\mathrm{a}}$ Dr $^{\mathrm{a}}$ Vanessa Soares Lara pela atenção e carinho que me dedicaram.

Aos docentes da Faculdade de Odontologia de Bauru - USP, responsáveis pela minha formação profissional.

Aos funcionários da Disciplina de Patologia da Faculdade de Odontologia de Bauru - USP, Cristina, Fatiminha, Fernando, Rodrigo e Sr. Valdir, pela amizade.

Aos colegas do curso de Doutorado Erick, Leda, Marta, Patrícia e Rosário, por todos os momentos de carinho, amizade e união que passamos juntos, vocês são pessoas especiais:

“Uma amizade conquistada é para sempre”

Aos pós-graduandos da Disciplina de Patologia da Faculdade de Odontologia de Bauru - USP, Aline, Ana Carolina, Andréa, Bethânia, Camila, Carlos, Érica, Janaína, João Adolfo, Lidiane, Luciana, Marie Fernanda, Maria Renata, Michele, Renata Falchete, Renata Consolaro, Renato, Simone, Sylvie, Tânia e Tiago pelo companheirismo.

Ao Prof. Valdir João Afonso pelo auxílio na correção ortográfica deste trabalho e pelo carinho com que me trata.

Ao Prof. Dr. José Roberto Pereira Lauris pela realização da análise estatística e ajuda sempre que precisei. 
A Rosário Zebedeski, sempre disposta a ajudar, pelo grande carinho e amizade, mesmo antes de sermos amigas de turma.

A Camila Medina pela paciência e dedicação com que me ajudou na ilustração desta tese.

A Daniela Barbosa Nicolielo pelos esclarecimentos e empréstimo de material sempre com muita presteza.

A Gisele Dalben pela elaboração do abstract.

Aos médicos e funcionários do setor de oncologia do Hospital Infantil Darcy Vargas, na pessoa da Dr ${ }^{\mathrm{a}}$. Maria Lydia Mello de Andrea pela oportunidade de realização desta tese e prontidão sempre que necessário.

A Dr ${ }^{\mathrm{a}}$. Delma Tostes Oliveira pelos esclarecimentos sempre que precisei.

Aos funcionários do setor de oncologia do Hospital Infantil Darcy Vargas, Cornélio, Maria e Vera que muito contribuíram.

As cirurgiãs-dentistas e funcionários do setor de odontologia do Hospital Infantil Darcy Vargas, na pessoa da Dr ${ }^{\mathrm{a}}$ Elvira Marana S. Bueno pela acolhida.

A Ana Rosa Maurício pela ajuda no desenvolvimento desta tese.

Ao Serviço de Arquivo Médico do Hospital Infantil Darcy Vargas, na pessoa da Dra ${ }^{\mathrm{a}}$ Maria Cristina C. L. M. Nogueira e seus funcionários Alaíde, Eliane, Mauro. Nena e Vilma, pela disponibilidade e presteza com que sempre me atenderam.

A Enf ${ }^{\text {a }}$ Keila Nunes e funcionários do SOPC pelo estímulo e companheirismo. 
Ao Dr. Edgar José Franco Mello Jr. Pelos muitos ensinamentos transmitidos.

Ao Dr. Paulo Eduardo de Souza pela ajuda e apóio.

A Dr ${ }^{\mathrm{a}}$. Ana Cristina X. Neves pelos esclarecimentos.

A todos os funcionários da Secretaria de Pós-graduação da Faculdade de Odontologia de Bauru.

A todos os funcionários da Biblioteca Ademir, César, Cybelle, Jane, Maria, Maria Helena, Roberto, Thereza, Valéria e Vera pela atenção e orientação que sempre me dedicaram.

A todos os funcionários da Faculdade de Odontologia de Bauru, USP, por colaborarem no anonimato.

A todos os pacientes em tratamento no Hospital Infantil Darcy Vargas e seus familiares, que mesmo estando num momento bastante difícil colaboraram com minha pesquisa. 


\section{AGRADECIMENTOS INSTITUCIONAIS}

À Direção da Faculdade de Odontologia de Bauru - USP, na pessoa de seu Diretor , Prof. Dr Luiz Fernando Pegoraro.

À Comissão de Pós-graduação da Faculdade de Odontologia de Bauru USP, presidida pela Prof ${ }^{a}$. Dr ${ }^{a}$.Maria Aparecida de Andrade Moreira Machado.

Ao Curso de Pós-graduação em Patologia Bucal da Faculdade de Odontologia de Bauru na pessoa seu coordenador Prof. Dr. Luís Antônio de Assis Taveira.

À Prefeitura Municipal de Bauru, na pessoa do Prefeito Tuga Angerami, ao Secretário Municipal de saúde Dr. Mario Ramos e aos cirurgiões-dentistas Dr. Carlos Alberto Caricati, Dra . Sílvia Dekon, Dra . Vera H. Tavares Lugo e demais funcionários que me possibilitaram a realização deste curso.

À Escola Joaquim Rodrigues Madureira, sob direção da $S r^{a}$. Judite Della Torres Jayme e Sra . Fátima Regina Lima Ribeiro e todos os funcionários.

Ao Hospital Infantil Darcy Vargas, São Paulo, na pessoa de seu Diretor Dr. Sérgio Antônio Bastos Sarrubbo pela oportunidade de realização deste trabalho. 


\section{SUMÁRIO}

LISTA DE FIGURAS X xiii

LISTA DE TABELAS Xiv

RESUMO Xvi

1 INTRODUÇÃO 1

2 REVISÃO DE LITERATURA

2.1 Leucemias 9

2.1.1 Conceito e características gerais 9

$\begin{array}{lll}2.1 .2 & \text { Classificação } & 10\end{array}$

$2.2 \quad$ Leucemia linfóide aguda 12

2.2.1 Incidência 12

2.2.2 Etiologia 13

2.2.3 Manifestações clínicas iniciais $\quad 14$

2.2.4 Tratamento e efeitos adversos 15

$\begin{array}{lll}\text { 2.3. } & \text { Mucosite bucal }\end{array}$

2.3.1 Conceito e características gerais 19

2.3.2 Fatores de risco para mucosite bucal 20

2.3.3 Patogênese da mucosite bucal 22

2.3.4 Agentes estomatotóxicos 27

2.3.5 Tratamento da mucosite bucal $\quad 29$

$3 \quad$ PROPOSIÇÃO 31

$4 \quad$ MATERIAL E MÉTODOS 35

4.1 População de Estudo e Seleção da Amostra 37

$4.2 \quad$ Registro dos Dados Clínicos 38 
4.3 Análise estatística 40

4.4 Comitê de Ética $\quad 40$

5 RESULTADOS 65

$\begin{array}{lll}5.1 & \text { Casuística } & 67\end{array}$

5.2 Associação da mucosite bucal com os fatores de risco para sua ocorrência 71 em pacientes com LLA

5.3 Freqüência da mucosite bucal em relação aos grupos de risco dos diferentes 76 protocolos de tratamento para LLA

5.4 Freqüência de mucosite bucal em relação a outras doenças sistêmicas e/ou 83 locais apresentadas pelo pacientes com LLA

$6 \quad$ DISCUSSÃO $\quad 85$

$7 \quad$ CONCLUSÃO 99

REFERÊNCIAS BIBLIOGRÁFICAS 103

$\begin{array}{ll}\text { ABSTRACT } & 115\end{array}$ 


\section{LISTA DE FIGURAS}

FIGURA 1 Representação esquemática das fases da mucosite bucal. 25

FIGURA 2 Formulário específico para coleta de informações clínicas. 41

FIGURA 3 Protocolo de tratamento da LLA de acordo com o GBTLI 93 para 43 pacientes de risco básico verdadeiro.

FIGURA 4 Protocolo de tratamento da LLA de acordo com o GBTLI 93 para pacientes de risco básico.

FIGURA 5 Protocolo de tratamento da LLA de acordo com o GBTLI 93 para pacientes de alto risco.

FIGURA 6 Protocolo de tratamento da LLA de acordo com o GBTLI 99 para pacientes de baixo risco.

FIGURA 7 Protocolo de tratamento da LLA de acordo com o GBTLI 99 para pacientes de alto risco.

FIGURA 8 Protocolo de tratamento da LLA de acordo com o ALL-BFM 95 para pacientes de baixo risco.

FIGURA 9 Protocolo de tratamento da LLA de acordo com o ALL-BFM 95 para pacientes de médio risco.

FIGURA 10 Protocolo de tratamento da LLA de acordo com o ALL-BFM 95 para pacientes de alto risco.

FIGURA 11 Protocolo de tratamento da LLA de acordo com o ALL-BFM 02 para pacientes de baixo risco.

FIGURA 12 Protocolo de tratamento da LLA de acordo com o ALL-BFM 02 para pacientes de risco intermediário.

FIGURA 13 Protocolo de tratamento da LLA de acordo com o ALL-BFM 02 para pacientes de alto risco.

FIGURA 14 Manifestação da mucosite bucal em pacientes com leucemia linfóide aguda em tratamento no Hospital Infantil Darcy Vargas em São Paulo. 


\section{LISTA DE TABELAS}

TABELA 1 Distribuição percentual da ocorrência de mucosite bucal em 67 pacientes oncológicos pediátricos com leucemia linfóide aguda. Hospital Infantil Darcy Vargas, São Paulo, 1994 a 2005.

TABELA 2 Distribuição percentual dos pacientes oncológicos pediátricos com LLA em relação ao gênero, idade e número iniciais de leucócitos/mm³. Hospital Infantil Darcy Vargas, São Paulo, 1994 a 2005.

TABELA 3 Evolução clínica dos pacientes oncológicos pediátricos com leucemia linfóide aguda de acordo com protocolos de tratamento (GBTLI 93, ALL-BFM 95, GBTLI 99 e ALL-BFM 2002) a que foram submetidos. Hospital Infantil Darcy Vargas, São Paulo, 1994 a 2005.

TABELA 4 Correlação entre a ocorrência da mucosite bucal e o gênero dos pacientes oncológicos pediátricos com leucemia linfóide aguda. Hospital Infantil Darcy Vargas, São Paulo, 1994 a 2005.

TABELA 5 Correlação entre a ocorrência da mucosite bucal e a idade dos 72 pacientes oncológicos pediátricos com leucemia linfóide aguda. Hospital Infantil Darcy Vargas, São Paulo, 1994 a 2005.

TABELA 6 Correlação entre a ocorrência da mucosite bucal e o número de 72 leucócitos iniciais dos pacientes oncológicos pediátricos com leucemia linfóide aguda. Hospital Infantil Darcy Vargas, São Paulo, 1994 a 2005.

TABELA 7 Distribuição percentual da ocorrência de mucosite bucal em relação aos protocolos de tratamento (GBTLI 93, ALL-BFM 95, GBTLI 99 e ALL-BFM 2002) utilizados pelos pacientes oncológicos pediátricos com leucemia linfóide aguda. Hospital Infantil Darcy Vargas, São Paulo, 1994 a 2005.

TABELA 8 Correlação entre a ocorrência de mucosite bucal com o gênero, a idade, a leucometria inicial e os protocolos de tratamento (GBTLI 93, ALL-BFM 95, GBTLI 99 e ALL-BFM 2002) utilizados pelos pacientes oncológicos pediátricos com leucemia linfóide aguda de acordo com a análise de regressão logística multivariada. Hospital Infantil Darcy Vargas, São Paulo, 1994 a 2005. 
TABELA 9 Distribuição percentual da ocorrência de mucosite bucal em 76 pacientes oncológicos pediátricos com leucemia linfóide aguda em relação aos grupos de risco do protocolo de tratamento GBLTI 93. Hospital Infantil Darcy Vargas, São Paulo, 1994 a 2005.

TABELA 10 Distribuição percentual da ocorrência de mucosite bucal em 77 pacientes oncológicos pediátricos com leucemia linfóide aguda em relação aos grupos de risco do protocolo de tratamento ALL-BFM 95. Hospital Infantil Darcy Vargas, São Paulo, 1994 a 2005.

TABELA 11 Distribuição percentual da ocorrência de mucosite bucal em 78 pacientes oncológicos pediátricos com leucemia linfóide aguda em relação aos grupos de risco do protocolo de tratamento GBLTI 99. Hospital Infantil Darcy Vargas, São Paulo, 1994 a 2005.

TABELA 12 Distribuição percentual da ocorrência de mucosite em pacientes 79 oncológicos pediátricos com leucemia linfóide aguda em relação aos grupos de risco do protocolo de tratamento ALL-BFM 2002. Hospital Infantil Darcy Vargas, São Paulo, 1994 a 2005.

TABELA 13 Distribuição percentual da ocorrência de mucosite bucal em pacientes oncológicos pediátricos com leucemia linfóide aguda em relação a outras doenças sistêmicas e/ou bucais apresentadas pelo paciente. Hospital Infantil Darcy Vargas, São Paulo, 1994 a 2005. 


\section{RESUMO}

A mucosite bucal está entre as principais complicações decorrentes do tratamento antineoplásico em pacientes com leucemia linfóide aguda (LLA). Entre os fatores de risco para sua ocorrência destacam-se a idade, o gênero e a leucometria inicial, além das drogas quimioterápicas com comprovada ação estomatotóxicas. O objetivo deste estudo foi investigar a prevalência e os fatores de risco para a mucosite bucal em pacientes com LLA submetidos a diferentes protocolos de tratamento quimioterápicos. Um total de 169 prontuários clínicos de pacientes oncológicos pediátricos submetidos a diferentes protocolos de tratamento para LLA no Setor de Oncologia Pediátrica do Hospital Infantil Darcy Vargas, na cidade de São Paulo, no período compreendido entre 1994 a 2005 foram, retrospectivamente, avaliados. Os dados demográficos (idade e gênero) e clínicos (leucometria inicial, protocolo de tratamento a que foi submetido, evolução, ocorrência de mucosite e outras lesões bucais) foram registrados. A associação da mucosite bucal com as variáveis clínicas e demográficas foi obtida pelos testes do qui-quadrado e análise de regressão logística multivariada. Os resultados demonstraram uma freqüência de mucosite bucal em 46\% dos pacientes oncológicos pediátricos com LLA sem correlação estatisticamente significativa entre sua ocorrência e o gênero $(\mathrm{p}=0,08)$, a idade $(\mathrm{p}=0,33)$ e a leucometria inicial $(\mathrm{p}=0,34)$. Na análise multivariada o protocolo de tratamento do grupo BerlimFrankfurt-Munique de 1995 (ALL-BFM 95), de acordo com as variáveis avaliadas neste estudo, mostrou ser o fator mais significativo $(p=0,009)$ para a ocorrência da mucosite bucal. Esses resultados fortemente sugerem uma maior estomatotoxicidade do protocolo ALL-BFM 95 comprovadas pela maior freqüência de mucosite bucal nos pacientes ontológicos pediátricos com LLA. Portanto, concluímos que a mucosite bucal deveria ser sistematicamente analisada nos centros especializados no tratamento da LLA que adotam diferentes protocolos de tratamento, visando não somente contribuir com a análise do grau de toxicidade das drogas quimioterápicas, mas principalmente, melhorar a qualidade de vida do paciente com base em condutas terapêuticas e profiláticas mais efetivas na prevenção de sua ocorrência.

Palavras-Chave: Mucosite. Quimioterapia. Criança. Leucemia linfóide aguda. 
1 INTRODUÇÃO 



\section{INTRODUÇÃO}

A leucemia linfóide aguda (LLA), caracterizada pela proliferação de células linfóides com maturação interrompida antes da diferenciação, consiste na neoplasia maligna mais comum da infância, com pico de incidência entre dois e cinco anos de idade $^{6,26,27,33,35,63}$. No Brasil, de dez a 15 casos de câncer que acometem crianças com menos de quinze anos de idade, quatro são de leucemia linfóide aguda ${ }^{39}$. A doença é mais comum em crianças brancas do que em negras (1,8:1) e em meninos do que em meninas $(1,2: 1)^{4,19,43}$.

A etiologia das leucemias agudas é desconhecida, mas muitas predisposições genéticas, fatores ambientais e virais tem sido associados à doença ${ }^{26}$. A radiação ionizante e a exposição ao benzeno foram relacionadas ao aumento do risco de LLA ${ }^{26}$, 33,34,35,38. Atualmente, existem evidências convincentes que as translocações cromossômicas são freqüentemente o primeiro ou o evento inicial da leucemia, ocorrendo durante o período pré-natal do desenvolvimento fetal $6,16,21,23,34$. Certas síndromes e algumas anormalidades cromossômicas como, por exemplo: a Síndrome de Down, a Síndrome de Bloom, a Anemia de Fanconi e a Ataxia-telangiectasia também tem sido relacionadas ao aumento do risco no desenvolvimento da LLA ${ }^{4,26,33,34,35}$.

Até metade do século passado, as leucemias, incluindo a LLA, eram consideradas, universalmente, doenças fatais ${ }^{43}$. O desenvolvimento de combinações terapêuticas com diversas drogas citotóxicas, com ou sem transplante de medula óssea, 
tem aumentado o percentual de cura da criança com LLA em mais de $80 \%$, quando diagnosticada precocemente e tratada em centros especializados ${ }^{23,34,39,43,46,47,49,50}$. Essa acentuada melhora nos resultados tem produzido um aumento na população de sobreviventes. Contudo, dos 75.000 novos casos de LLA, que são diagnosticados anualmente em todo o mundo, em torno de 60.000 (80\%) não têm acesso a essas modernas formas de tratamento e são, portanto excluídos deste processo de cura ${ }^{43}$.

O tratamento da LLA varia de dois a três anos e os protocolos terapêuticos são constituídos basicamente de cinco fases: indução da remissão, intensificaçãoconsolidação, reindução, prevenção da leucemia no sistema nervoso central e continuação ou manutenção da remissão ${ }^{10,11,26,32,48,51,52}$.

Embora a LLA deva sempre ser considerada uma doença grave, a identificação de vários fatores prognósticos permite a estratificação dos pacientes em grupos de risco, o que possibilita uma abordagem terapêutica diferenciada. Os grupos de maior risco são tratados com terapias mais intensas, cada vez mais eficazes, enquanto os grupos de baixo risco apresentam melhor sobrevida, podendo ser poupados dos efeitos deletérios da terapêutica ${ }^{4,19,20,34,42,46,48,49}$.

Entre os grandes grupos internacionais de estudo das leucemias, os alemães se destacam por conseguirem as maiores taxas de sobrevida tendo difundido seus ensinamentos por todo o mundo por meio do protocolo ALL-BMF (acute lymphoblastic leukemia - Berlim-Frankfurt-Munique) $)^{32,51,52}$.

No Brasil, o Grupo Brasileiro de Tratamento da Leucemia Infantil (GBTLI) tem apresentado, sistematicamente, protocolos de tratamento para LLA baseando-se sempre nas experiências do protocolo utilizado anteriormente com modificação de dosagens quimioterápicas, substituição ou combinação de drogas e eliminação de seqüelas, visando melhorar as taxas de sobrevida bem como a cura dos pacientes ${ }^{11}$. 
Mesmo com os altos índices de cura, aproximadamente 20\% a 30\% das crianças com LLA apresentam recidiva da doença a qual ocorre, geralmente nos primeiros cinco anos após o diagnóstico ${ }^{26,34}$. O sítio de recaída pode ser medular ou extramedular, atingindo qualquer órgão ou tecido como sistema nervoso central, testículo, olhos, ovário e útero $20,21,34,42$.

As manifestações clínicas gerais da leucemia são resultado direto da invasão medular que resulta em citopenias (anemia, trombocitopenia, leucopenia e/ou neutropenia) ${ }^{26,41,60}$. Além disso, devido a imunosupressão causada pela terapia antineoplásica algumas complicações clínicas em crianças submetidas à quimioterapia ou radioterapia são esperadas durante o tratamento. Dentre estas complicações destacam-se a febre (que pode estar associada à leucemia ou a infecção), fraqueza, fadiga, infecções, perda de apetite e peso, sangramentos, manchas roxas na pele (hematomas e equimoses), sudorese noturna, dor óssea e articular, dor abdominal, adenomegalia, aumento do tamanho dos testículos, dor de cabeça e vômitos (devido ao envolvimento do sistema nervoso central) $)^{4,26,28,54}$.

Na boca, a mucosite representa a complicação mais comum da citotoxicidade causada pela quimioterapia e radioterapia durante o tratamento dos pacientes com $\operatorname{LLA}^{30,40,57,58,59}$. A manifestação clínica da mucosite bucal é variável podendo ocorrer na forma de lesões atróficas e/ou eritematosas mantendo a mucosa bucal íntegra ou em casos mais graves como extensas áreas ulceradas causando dor intensa ${ }^{8,17,58,60}$. Adicionalmente aos sintomas da mucosite bucal e seu impacto na qualidade de vida dos pacientes com LLA, sua ocorrência representa um significante fator de risco para infecções sistêmicas, particularmente em pacientes neutropênicos ${ }^{8,13,28,31,55,58,59 .}$

A patogênese da mucosite bucal ainda não está totalmente esclarecida, entretanto, mecanismos diretos e indiretos têm sido associados à sua ocorrência. A lesão 
da mucosa bucal causada diretamente pela radiação ou quimioterapia interfere com o turnover normal do epitélio e induz a apoptose $\mathrm{e}^{8,31,58,59}$. Efeitos citotóxicos indiretos que resultam da liberação de mediadores inflamatórios, da perda dos constituintes salivares protetores e da neutropenia induzida pelo tratamento tem sido considerados fatores contribuintes na ocorrência da mucosite bucal ${ }^{30,56,58}$.

A incidência e gravidade da mucosite bucal são influenciadas pelo tratamento antineoplásico (medicamentos administrados, intensidade das dosagens medicamentosas, duração do tratamento) e também por fatores relacionados ao paciente ${ }^{3,18,28,42}$.

Medicamentos como o fluorouracil, o metrotrexate, a daunorrubicina e a ciclofosfamida, freqüentemente utilizados nos protocolos de tratamento da LLA, exibem maior toxicidade na mucosa bucal ${ }^{1,11,29,52}$ sendo comumente associados a ocorrência de mucosite bucal.

O conceito de que a terapia da LLA seria curativa se o tratamento precoce fosse suficiente para erradicar as células malignas antes que elas se tornem resistentes às drogas induziu o desenvolvimento de protocolos progressivamente mais intensivos com o aumento do número de medicamentos, especialmente para pacientes com alto risco de recaída ${ }^{43}$. Consequentemente, efeitos colaterais como a ocorrência de mucosite bucal também são comumente esperados.

Sabendo-se que os protocolos de tratamento da LLA utilizados nos centros especializados são diferentes e freqüentemente adaptados, a investigação da mucosite bucal deveria ser sistematicamente avaliada visando, não somente identificar os possíveis fatores de risco para sua ocorrência, mas principalmente melhorar a qualidade de vida do paciente oncológico por meio de condutas terapêuticas e profiláticas, locais ou sistêmicas, mais direcionadas e efetivas. 
2 REVISÃO DE LITERATURA 



\section{REVISÃO DE LITERATURA}

\section{$\underline{2.1 \text { Leucemias }}$}

\subsubsection{Conceito e características gerais}

As leucemias são as neoplasias malignas que afetam os glóbulos brancos do sangue e correspondem a $30 \%$ de todos os casos de câncer em crianças. A alteração básica nas leucemias consiste na proliferação de um clone de células hematopoiéticas anormais com alterações na diferenciação, regulação e apoptose ${ }^{38}$. Sua etiologia permanece obscura, entretanto, mecanismos genéticos e ambientais parecem estar envolvidos na sua patogênese $\mathrm{2}^{26,33,34,35,38}$.

A leucemia é uma doença que evolui pelo acúmulo de mutações dentro de um clone de células resultando em uma progressiva diversificação genética, seguida por uma "seleção natural" de subclones mutantes dominantes. Os resultados clínicos dependem, não somente da natureza do clone de células leucêmicas, mas do tempo de evolução até que os sintomas patológicos sejam reconhecidos, do estabelecimento do diagnóstico até o início do tratamento ${ }^{23}$.

A doença tem como principal característica à proliferação invasiva de células jovens (blásticas) anormais na medula óssea, que substituem as células sangüíneas normais. Qualquer classe de leucócitos, das linhagens granulocítica, monocítica ou linfóide, tem a possibilidade de sofrer transformação maligna ${ }^{38,54}$. Após a invasão medular, os elementos blásticos (células anormais) invadem o sangue circulante, se 
exteriorizando e dessa forma invadindo todo o organismo, compondo a história natural da doença. Antes de outras estruturas, inicialmente, são invadidos os gânglios, o baço e o fígado, que são ou foram estruturas hematopoiéticas ${ }^{37}$.

\subsubsection{Classificação}

O propósito de uma classificação para as leucemias é identificar entidades biológicas distintas as quais diferem na etiologia, mecanismos de leucogênese, características clinicopatológicas e prognósticos, pois o tratamento adequado para distintas entidades é diferente, sendo essencial para os cuidados ideais do paciente ${ }^{2}$.

As leucemias são classificadas de acordo com sua histogênese, célula primária hematopoiética afetada (mielóide ou linfóide) e comportamento clínico (aguda ou crônica) $)^{19,22,38,41}$.

Para $\mathrm{McKENNA}^{38}$, as principais classificações diagnósticas são:

- Leucemia não-linfocítica aguda (LNLA) ou Leucemia mielóide aguda (LMA):

é a proliferação de células mielóides imaturas. O diagnóstico é realizado pela presença de pelo menos $30 \%$ de mieloblastos na medula óssea. Seus sintomas incluem febre, fadiga, palidez, sangramento gengival, petéquias e infecções locais. A LMA é classificada em sete subtipos celular, o que é bastante importante para a terapêutica e prognóstico.

- Leucemia linfóide aguda (LLA): é a proliferação clonal de células linfóides com a maturação interrompida antes da diferenciação. Ocorre de $10 \%$ a $15 \%$ em adultos e $75 \%$ em crianças. As manifestações clínicas são semelhantes as da LMA, mas com alta incidência de comprometimento do sistema nervoso central. 
- Leucemia mielóide crônica (LMC): é uma desordem clonal, resultando em hiperplasia mielóide na medula e presença de células mielóides no sangue, com translocação dos cromossomos t(9;22). Afeta todas as idades, embora a média de idade é 53 anos. Os sintomas mais comuns são fadiga, anorexia, perda de peso e esplenomegalia.

- Leucemia linfóide crônica (LLC): é a leucemia mais comum depois dos 50 anos de idade. Sua etiologia é incerta, mas em $40 \%$ dos pacientes é observada nas células leucêmicas uma alteração do cromossomo 12.

A diferenciação entre a leucemia linfóide aguda e a leucemia mielóide aguda, além de alguns sinais clínicos característicos, é realizada pela identificação de expressões genéticas, reação de antígenos que definem o tipo celular ou a fase de diferenciação e alterações cromossômicas ou moleculares ${ }^{16,19,27}$.

Outras formas de classificação também são encontradas para as leucemias agudas como, por exemplo ${ }^{2}$ :

- classificação pela morfologia e citoquímica complementada pela imunofenotipagem, como proposto pelo grupo Francês-Americano-Britânico (FAB);

- classificação pela morfologia, imunofenotipagem e citogenética como proposto pelo grupo MIC (morfologia, imunofenotipagem e citogenética);

- classificação somente pela imunofenotipagem, como proposto pelo Grupo Europeu de Classificação Imunológica de Leucemia (EGIL);

- classificação por eventos antecedentes; 
- classificação pela natureza da célula originária ou progenitora na qual a mutação leucogênica ocorreu.

As leucemias agudas, se não tratadas, evoluem de forma agressiva que freqüentemente resultam na morte do paciente dentro de poucos meses, sendo que as crônicas evoluem de forma mais indolente, permitindo uma sobrevida mais longa ${ }^{26,34,41}$.

\section{$\underline{\text { 2.2 Leucemia linfóide aguda }}$}

\subsubsection{Incidência}

A leucemia linfóide aguda ocorre em todas as idades, mas é mais comum em crianças sendo o maior pico de incidência entre dois e cinco anos de idade $^{21,24,25,26,33,43,63}$. Representa $75 \%$ de todas as leucemias em pacientes com menos de 15 anos de idade, com um subseqüente declínio das taxas de ocorrência entre oito e dez anos de idade. Nos Estados Unidos da América, por exemplo, a incidência de leucemia linfóide aguda em crianças brancas $(32,9 \%)$ é quase duas vezes maior do que a incidência em crianças negras $(16,9 \%)^{24}$.

Para PUI; EVANS ${ }^{47}$, em 1998, quase 4.000 casos de LLA são diagnosticados anualmente nos EUA, dos quais aproximadamente dois terços são crianças e adolescentes, apresentando uma taxa de cura em torno de $80 \%$.

De acordo com GRAVES ${ }^{23}$, no Reino Unido, o risco de uma criança desenvolver leucemia linfóide aguda é de aproximadamente uma em 2000 crianças, com 400 a 450 novos casos por ano. Taxas de cura em torno de $75 \%$ podem ser alcançadas combinando quimioterapia, mas as taxas de sucesso variam de $10 \%$ a $90 \%$ de acordo com os subtipos biológicos diferentes da doença.

A incidência de leucemia aguda no Japão, por ano, em crianças menores de 15 anos de idade é de três a quatro crianças por um milhão, sendo $25 \%$ aproximadamente de LMA e $70 \%$ de LLA ${ }^{36}$. 
No Brasil, o câncer infantil representa cerca de 0,5 a 3\% de todas as neoplasias malignas e, em geral, a incidência total de tumores malignos na infância é maior no gênero masculino. Em torno de 10 a 15 casos de câncer, entre indivíduos com menos de 15 anos de idade no Brasil, quatro são de LLA e as taxas de cura variam de $70 \%$ a $80 \%$ dos $\operatorname{casos}^{39}$.

\section{$\underline{\text { 2.2.2 Etiologia }}$}

A LLA é considerada uma doença heterogênea em termos de morfologia, imunofenotipagem, citogenética, características moleculares, resposta inicial ao tratamento e resultados clínicos ${ }^{22}$.

Embora, a leucemia infantil tenha sido o tema de inúmeras investigações epidemiológicas, sua etiologia em muitos casos continua desconhecida. Alguns fatores geralmente são relacionados com o aumento do risco para o desenvolvimento da leucemia linfóide aguda como gênero masculino, faixa etária entre dois e cinco anos, raça branca, nível sócio econômico alto e exposição à radiação ainda em útero bem como, após o nascimento. Outros fatores associados com o aumento do risco de LLA, porém com menor caracterização são alto peso da criança ao nascer, história materna de abortos, mães mais velhas e algumas exposições ambientais ${ }^{33,34,35}$.

Segundo HASTINGS ${ }^{26}$, a etiologia das leucemias agudas é desconhecida, mas muitas predisposições genéticas, fatores ambientais e virais, radiação ionizante, exposição ao benzeno e irmãos, principalmente gêmeos idênticos estão relacionados com um aumento no risco do desenvolvimento das leucemias. Certas síndromes e anormalidades cromossômicas também são associadas à alta incidência do desenvolvimento das leucemias (síndrome de Down, síndrome de Bloom, ataxiatelangiectasia). Nessas síndromes estão presentes os denominados sítios frágeis, em 
alguns cromossomos. Esses locais representam zonas de fácil quebra, dando origem à instabilidade cromossômica, representando locais de difícil reparo do DNA após a exposição do indivíduo a agentes mutagênicos ambientais ${ }^{34}$.

Atualmente existem evidências convincentes que as translocações cromossômicas são freqüentemente o primeiro ou o evento inicial da leucemia, ocorrendo durante a fase pré-natal no desenvolvimento do feto. A anormalidade genética estrutural mais comum na criança leucêmica é a fusão de dois genes (TEL e AML1). Isso é gerado pela translocação cromossômica entre os cromossomas 12 e 21 . Quebras simultâneas no gene TEL (cromossoma 12) e no gene AML1 (cromossoma 21) são seguidas por um erro-propenso no reparo unindo os genes separados TEL e AML1, formando um gene de fusão. Em outras translocações cromossômicas as quebras no DNA ocorrem sempre em regiões não-codificadas ${ }^{23}$.

\subsubsection{Manifestações clínicas iniciais}

Aproximadamente $66 \%$ das crianças com leucemia linfóide aguda apresentam os sinais e sintomas da doença por um período menor de quatro semanas antes do diagnóstico da doença. Os primeiros sintomas da LLA geralmente não são específicos e incluem anorexia, irritabilidade e letargia. Com a evolução da doença, progressivamente ocorre falha na medula óssea gerando anemia, sangramento (trombocitopenia) e febre (neutropenia) $)^{4}$.

As manifestações clínicas da leucemia linfóide aguda ${ }^{26,34,37,41,60}$ são um resultado direto da invasão medular e resultantes citopenias (anemia, trombocitopenia, leucopenia e/ou neutropenia) e envolvimento extra-medular. Crianças com anemia podem ter palidez, fatiga, taquicardia ou evidência de congestiva falha cardíaca. Infecção pode estar presente no diagnóstico, causando febre, provavelmente secundária a neutropenia. Sangramento moderado é comum, manifestado como petéquias, equimose, sangramento 
gengival ou epistaxe. Linfadenopatia ou uma massa mediastinal extensa pode ocorrer resultando em um comprometimento respiratório ou cardiovascular.

Em 5\% das crianças aproximadamente, ocorre envolvimento do sistema nervoso central, sendo assintomático na maioria dos pacientes, embora possa ocorrer sinais e sintomas do aumento da pressão intracraniana (paralisia cranial do nervo VI, dor de cabeça pela manhã, vômitos, edema papilar). Envolvimento testicular ocorre em $2 \%$ a $5 \%$ dos meninos. Dor óssea está presente em aproximadamente $25 \%$ das crianças, em crianças muito novas, irritabilidade e recusa para andar são sintomas iniciais (pode ser resultado da infiltração leucêmica direta do periósteo ou expansão da cavidade medular pelas células leucêmicas ${ }^{26}$.

Para NEVILLE; DAMN; $\operatorname{ALLEN}^{41}$ e o Instituto Nacional do Câncer ${ }^{39}$, manifestações clínicas da leucemia aguda são secundárias à proliferação excessiva de células imaturas (blásticas) da medula óssea, que infiltram os tecidos do organismo, tais como: amígdalas, linfonodos (ínguas), pele, baço, rins, sistema nervoso central (SNC) e outros. A fadiga, palpitação e anemia aparecem pela redução da produção dos eritrócitos pela medula óssea e subseqüente reduzida capacidade de transporte de oxigênio do sangue. Infecções que podem levar ao óbito são causadas pela redução dos leucócitos normais.

Os pacientes leucêmicos também podem reclamar de ferimentos fáceis e problemas de sangramento causado pela falta de plaquetas sangüíneas (trombocitopenia) $)^{26,41,54,60}$.

\subsubsection{Tratamento e efeitos adversos}

O tratamento da LLA começa com o correto diagnóstico e pela sua complexidade deve ser realizado em centro especializado. 
A confirmação diagnóstica é realizada por meio do exame citológico do sangue periférico, da medula óssea e do líquor. O diagnóstico da LLA é estabelecido quando $25 \%$ ou mais das células nucleadas da medula óssea são linfoblastos. Geralmente, são realizados os seguintes exames do sangue periférico ou da medula óssea ${ }^{14}$ :

- citomorfologia e citoquímica;

- imunofenotipagem;

- citogenética convencional;

- o exame de biologia molecular tem sido realizado posteriormente como marcador da doença residual mínima.

Estabelecido o diagnóstico e determinado o protocolo de tratamento a ser utilizado, o paciente é incluído, de acordo com critérios específicos, em um grupo de risco de recaída da doença determinando assim a escolha do tratamento adequado. A estratificação em grupos de risco é determinada com base na idade do paciente, leucometria inicial, ausência ou presença de translocações genéticas e contagem de células leucêmicas no sangue periférico no D8 após o início da quimioterapia ${ }^{32}$.

Diversos grupos internacionais de estudo de LLA deram pesos distintos a estes e outros fatores (acometimento do SNC, massa mediastinal, tamanho do fígado e do baço, etc.) de estratificação dos pacientes em diferentes grupos de risco tornando difícil a comparação dos resultados entre as terapias ${ }^{11}$.

A divisão dos grupos de risco nos diferentes protocolos de tratamento da LLA $^{10,11,51,52}$ é variável; por exemplo, no protocolo GBTLI 93, elaborado por brasileiros, os pacientes são divididos em grupos de risco básico verdadeiro, risco básico e alto risco enquanto que no protocolo do grupo europeu ALL-BFM 95 ocorre a estratificação em pacientes de baixo, médio e alto risco. $\mathrm{O}$ protocolo mais recente do grupo brasileiro de tratamento da LLA, o protocolo GBTLI 99, divide os pacientes em 
apenas dois grupos, ou seja, o de baixo e alto risco; por outro lado no último protocolo do grupo europeu ALL-BFM 02 os pacientes são distribuídos em risco básico, risco intermediário e alto risco.

A terapia antineoplásica da LLA baseada na quimioterapia e/ou radioterapia é determinada pelo protocolo de tratamento sendo, no Brasil, os protocolos do Grupo Brasileiro de Tratamento da Leucemia Infantil (GTBLI) e do Grupo Europeu BerlimFrankfurt-Munique (ALL- BFM) os mais freqüentemente utilizados.

Estes protocolos terapêuticos para LLA são divididos basicamente em cinco fases: indução da remissão, intensificação-consolidação, reindução, prevenção da leucemia no sistema nervoso central e continuação ou manutenção da remissão ${ }^{4,10,11,26,32,42,43,47,48}$.

A primeira fase do tratamento, a terapia de indução, tem por objetivo induzir uma remissão clínica completa (RCC) da doença em quatro semanas, isto é, restaurar a hematopoiese normal com desaparecimento de toda a sintomatologia clínica associada. Essa fase geralmente utiliza no mínimo três drogas, glicocorticóide, vincristina, asparaginase e/ou daunomicina. Com bom suporte antiinfeccioso, hemoterápico e metabólico, a taxa de RCC esperada é de 96\% a 99\%. Após essa fase uma resposta clínica incompleta indica pior prognóstico, com altos riscos de falha terapêutica ${ }^{26,32,34,42,43,47}$.

Consolidação ou intensificação constitui uma fase de tratamento intensivo, incluindo vários agentes quimioterápicos, aplicada logo após a obtenção da remissão da doença. O objetivo dessa fase consiste em evitar o surgimento de clones resistentes às drogas e é capaz de promover remissões mais prolongadas e maior porcentagem de cura. Crianças portadoras de LLA, com exceção daquelas com LLA derivadas de 
células B maduras, necessitam de tratamento prolongado, com duração total de dois a três anos, para evitar recidiva da doença ${ }^{26,32,34,43,49}$.

O tratamento pré-sintomático do SNC é um componente essencial dos regimes terapêuticos e consiste de aplicações intratecais periódicas de metrotexate/citarabina e dexametasona, durante todo o tratamento ${ }^{4,11,32,34,51}$.

A fase de manutenção da quimioterapia, na maioria dos protocolos terapêuticos tem como base o uso diário da 6-mercaptopurina, acompanhada de doses semanais de metotrexate e pulsos adicionais de vincristina e prednisona ${ }^{10,11,32,51,52}$.

A quimioterapia combinada constitui o eixo principal no tratamento da LLA há mais de $25 \operatorname{anos}^{12}$ e a utilização de diversas drogas citotóxicas tem aumentado o percentual de cura da criança portadora de $\operatorname{LLA}^{34,43}$.

Durante o tratamento da LLA alguns efeitos colaterais decorrentes da quimioterapia são esperados como, por exemplo, náuseas, vômitos, diarréia e mucosite gastrointestinal. Manifestações cutâneas como eritema, erupções maculopapilar, dermatite exfoliativa, alopecia, hiperpigmentação e fotosensibilidade bem como convulsões e neuropatias periféricas também podem ocorrer ${ }^{4,10,11,26,28,54}$.

$\mathrm{Na}$ boca, as complicações incluem mucosite, infecções (bacteriana, viral e fúngica), hemorragia, xerostomia, complicações neurológicas e nutrição inadequada que resultam da ação direta e/ou indireta dos agentes quimioterápicos sobre a mucosa bucal, devido a mielossupressão induzida pela terapia. ${ }^{30,40,57,58,59,61}$. Enfatiza SONIS $^{61}$, que a fonte sepsia documentada com mais freqüência no paciente canceroso com agranulocitose é a boca.

As infecções bacterianas contribuem com a morbidade e mortalidade em pacientes mieloimunosuprimidos, e esses pacientes apresentam comprometimento bucal em $25 \%$ a $50 \%$ das septicemias febris ${ }^{28,37,41,57}$. 
Entre as infecções de origem viral que se manifestam no paciente com LLA destacam-se o herpes vírus simples, o herpes zoster e o citomegalovírus. A presença de mucosite bucal e dor pode prejudicar a habilidade do paciente comer e engolir, causando significantes problemas nutricionais e aumentando a sensação de sofrimento e tristeza do paciente $28,37,41,57$.

\subsection{Mucosite bucal}

\subsubsection{Conceito e características qerais}

Entre as complicações bucais decorrentes do tratamento antineoplásico, a mucosite é a forma mais comum de estomatotoxicidade direta ocorrendo especialmente na mucosa orofaríngea e gastrointestinal $1^{5,9,17,61}$.

A ocorrência de mucosite bucal varia de $40 \%$ a $60 \%$ em pacientes submetidos a protocolos quimioterápicos para tratamento de câncer ${ }^{45,56,67}$. Nos pacientes sob condicionamento para transplante de medula óssea esse valor pode chegar a $75 \%$ e quando ao tratamento quimioterápico é associado a radioterapia esse valor pode atingir $90 \%$ de ocorrência ${ }^{5}$.

TORRES-PEREIRA $^{64}, 2002$, em pesquisa retrospectiva realizada analisando os fatores de risco para o desenvolvimento de mucosite bucal em pacientes com LLA submetidos ao transplante de medula óssea, concluiu que em torno de $90 \%$ dos pacientes de sua amostra desenvolveram mucosite bucal.

Clinicamente, a mucosite bucal é caracterizada inicialmente por uma área eritematosa na mucosa bucal podendo evoluir para uma ulceração, resultando em dor intensa, desconforto, disfagia, disgesia ${ }^{9,17,30}$. As áreas mais atingidas são áreas de mucosa bucal não queratinizadas, como mucosa jugal, labial e superfície lateral e 
ventral da língua. Normalmente às superfícies dorsal da língua e palato duro não são envolvidas pela lesão ${ }^{55,61}$.

Em um estudo realizado por WOO et al. ${ }^{67}$, com 60 pacientes que receberam transplante de medula óssea, 75\% dos pacientes desenvolveram mucosite bucal após a quimioterapia ou radiação corpórea total ou ambos na preparação para o transplante e as áreas mais atingidas na mucosa bucal foram as regiões não-queratinizadas como o assoalho bucal, o freio lingual, a mucosa vestibular, jugal e labial.

A manifestação clínica da mucosite bucal é observada entre cinco a sete dias após a administração da quimioterapia. Se a medula óssea do paciente não estiver muito afetada pela quimioterapia, a mucosite bucal será autolimitada e tenderá a cicatrizar espontaneamente em cerca de duas semanas ${ }^{45,61,67}$.

O paciente com mucosite bucal apresenta importantes problemas nutricionais o que aumenta, significativamente, a sensação de sofrimento e tristeza, bem como o tempo de hospitalização do mesmo. Adicionalmente, ocorre um aumento no custo do tratamento que neste caso torna-se associado a terapia opióide, dieta líquida suplementar, nutrição parenteral, internação, profilaxia ou controle de infecções secundárias $^{17,28,31,58,59}$.

\subsubsection{Fatores de risco para mucosite bucal}

A ocorrência e a gravidade da mucosite bucal parece estar diretamente correlacionada ao tratamento antineoplásico (medicamentos administrados, intensidade das dosagens medicamentosas, freqüência da administração, duração do tratamento) e também por fatores relacionados ao paciente como idade, gênero, leucometria, estado nutricional e higiene bucal $3,18,28,30,42,55,56$.

Em estudo realizado por WARDLEY et al. ${ }^{66}$, em 2000, com 365 pacientes oncológicos, foi analisada a correlação do grau da mucosite bucal com alguns fatores de 
risco como idade, utilização de fatores de crescimento e regime de tratamento (drogas usadas), por meio da análise de regressão multivariada concluíram que o único fator de risco independente para a manifestação da mucosite bucal foi o regime de condicionamento para tratamento, principalmente quando o melfalan era utilizado.

Com relação aos fatores inerentes ao paciente, SONIS; FAZIO; FANG ${ }^{61}, 1996$, relatam que quanto mais jovem o paciente maior é a possibilidade da quimioterapia afetar a cavidade bucal. Segundo os autores cerca de $40 \%$ de todos os pacientes submetidos à quimioterapia desenvolvem efeitos colaterais bucais e em crianças com menos de 12 anos de idade, este número eleva-se para 90\%. Embora os pacientes neste grupo etário tenham tendência a desenvolver tumores malignos que causam problemas bucais, também parece provável que o índice mitótico elevado das células da mucosa bucal contribui como fator adjuvante para a mucosite bucal neste grupo etário ${ }^{45}$.

Além disso, SONIS; FAZIO; FANG ${ }^{61}$ afirmam que os pacientes jovens desenvolvem mucosite bucal mais grave que os pacientes de maior faixa etária, quando submetidos aos mesmos protocolos de tratamento, para os mesmos tipos de doenças. As manifestações de mucosite bucal em jovens requereriam menos tempo para a completa cicatrização se comparados aos pacientes mais velhos.

Outro fator importante na ocorrência de mucosite bucal refere-se a higiene bucal que, quando deficiente, bem como a presença de infecção odontogênica ou periodontal preexistente aumentam o risco de desenvolver uma complicação bucal durante os períodos de mielossupressão induzida pela quimioterapia ${ }^{3,30,31,55,61}$.

Por causa da microbiota bucal, a perda da integridade epitelial ocasionada pela mucosite bucal, especialmente em pacientes mielossuprimidos, faz com que haja um acentuado aumento no risco de bacteremia e septicemia e conseqüentemente estas infecções podem causar morbidade e/ou óbito ${ }^{18,45,56,58}$. 
Para WOO et al. ${ }^{67}, 1993$, é possível constatar que pacientes recebendo o mesmo protocolo quimioterápico, nas mesmas dosagens, na mesma faixa etária e com padrão similar da higiene bucal, não desenvolveriam o mesmo grau de mucosite, sendo, portanto, fundamental salientar uma variação individual específica observada em cada paciente.

\subsubsection{Patogênese da mucosite bucal}

De acordo com o modelo proposto por SONIS ${ }^{56}$ 1998, para explicar a patogênese da mucosite bucal, sua ocorrência pode ser dividida em quatro fases, sendo cada fase interdependente como conseqüência de uma série de atividades biológicas mediadas por citocinas, pelo efeito direto de drogas quimioterápicas sobre o epitélio, pela microbiota bucal e pela condição da medula óssea do paciente. Em 2004 este modelo foi revisto por SONIS, S.T. ${ }^{58}$ e colaboradores sendo incluída uma quinta fase neste processo patogênico, a saber:

1. fase de iniciação,

2. fase da reação primária a lesão,

3. fase do sinal e amplificação,

4. fase da ulceração e,

5. fase da cicatrização.

A primeira fase, de iniciação ${ }^{56,58}$, ocorre rapidamente após a administração da radioterapia ou quimioterapia, causando danos diretos ou não no DNA. As quebras nas fileiras de DNA resultam em lesão celular direta das células basais do epitélio e posteriormente, das células da submucosa. Simultaneamente, seria gerada uma espécie de oxigênio reativo (importante mediador do evento biológico) que desencadearia outros eventos. Embora, neste estágio a mucosa pareça íntegra e normal, uma seqüência de eventos já se iniciou na camada submucosa terminando com a destruição da mucosa. 
Na segunda fase, da reação primária a lesão ${ }^{56,58}$, os danos causados no DNA diretamente ou não e a espécie de oxigênio reativo iniciam uma interessante e complexa série de eventos, que resultam na ativação de vários mediadores e citocinas como o fator de necrose tumoral $\alpha$ (TNF- $\alpha$ ), e as interleucinas IL-1ß e IL-6 resultando em lesão no tecido e morte das células da camada submucosa e posteriormente das células da camada basal do epitélio.

$\mathrm{Na}$ fase de sinalização e amplificação, a terceira fase do processo ${ }^{56,58}$, além dos efeitos diretos sobre as células da mucosa, as citocinas pró-inflamatórias exercem uma ação indireta na amplificação do dano tecidual iniciado pela radioterapia e/ou quimioterapia. Como conseqüência dessa fase, embora o tecido ainda possa parecer normal, pois o foco do evento está ocorrendo na submucosa e camada basal do epitélio, o tecido está alterado biologicamente.

A fase de ulceração ${ }^{56,58}$, consiste na fase mais sintomática e talvez, a mais complexa, com áreas de erosão recobertas por uma pseudomembrana. Secundariamente, ocorre colonização bacteriana na lesão provendo uma fonte de lipopolissacarídeos as quais estimulam a liberação de citocinas do tecido conjuntivo de sustentação ao redor das células, promovendo um maior dano ao tecido.

$\mathrm{Na}$ última fase, a de cicatrização ${ }^{56,58}$, ocorre a renovação da proliferação e diferenciação celular, resultando na cicatrização do tecido afetado e restabelecimento da microbiota local. 


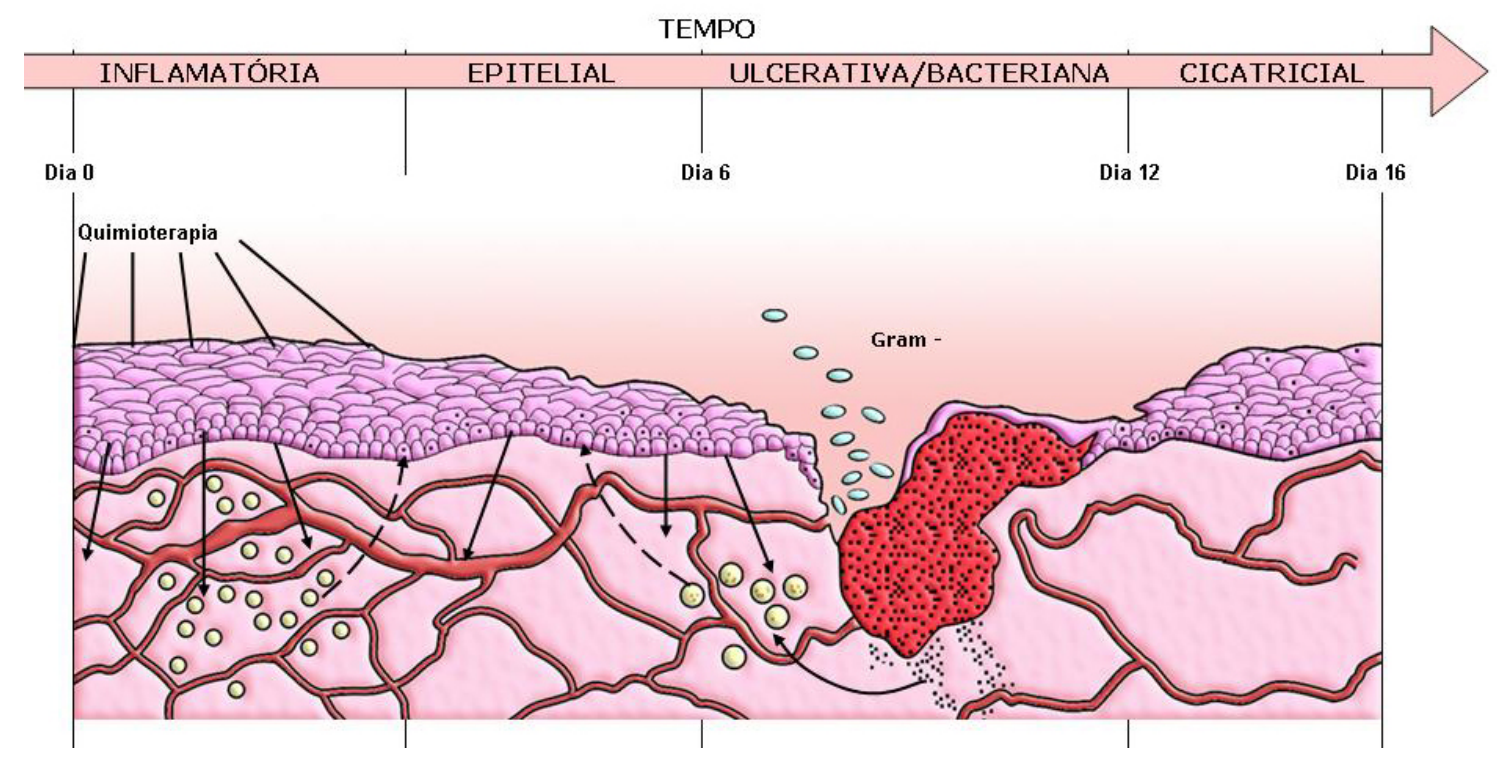

FIGURA 1: Representação esquemática das fases da mucosite bucal.

As quatro fases da mucosite: a fase inflamatória/vascular ocorre pouco tempo após a administração da quimioterapia, são liberadas citocinas do tecido epitelial, incluindo fator $\alpha$ de necrose tumoral, interleucina 1(IL-1) e interleucina 6 (IL-6). A radiação ionizante também incita a liberação de citocinas do tecido conjuntivo adjacente. É provável que essas citocinas causem dano no tecido local iniciando o desenvolvimento da mucosite. O aumento da vascularização causada pela IL-1 pode resultar em concentrações adicionais de drogas citotóxicas na mucosa. O aumento da celularidade submucosa é evidente nesta fase. $\mathrm{Na}$ fase epitelial ambos radiação e quimioterapia especialmente com drogas que atuam na fase $\mathrm{S}$ do ciclo celular dificultam a divisão celular da camada basal do epitélio, resultando em redução da renovação epitelial, atrofia e ulceração, sendo, posteriormente exacerbada pela ação de trauma funcional. A fase ulcerativa/bacteriológica consiste na mais sintomática e talvez a mais complexa, com áreas de erosão recobertas por uma pseudomembrana. Secundariamente ocorre colonização bacteriana na lesão provendo uma fonte de lipopolissacarídeos as quais estimulam a liberação de citocinas do tecido conjuntivo de sustentação ao redor das células e geralmente esta fase coincide com a máxima neutropenia do paciente. A fase de cicatrização consiste na renovação da proliferação e diferenciação epitelial, normalização da contagem de células sangüíneas brancas periféricas e restabelecimento da microbiota local. Adaptado SONIS ${ }^{56}, 1998$. 


\subsubsection{Aqentes estomatotóxicos}

De acordo com EPSTEIN; SCHUBERT ${ }^{18} 1999$, as drogas quimioterápicas são capazes de interferir em diferentes fases do ciclo celular, atingindo tanto células tumorais como células saudáveis. Explica-se a razão do uso de drogas de elevada toxicidade em muitos tipos de câncer, em função da alta taxa mitótica dos tumores malignos, sendo que altas doses de quimioterapia e também de radioterapia afetam diretamente a proliferação das células epiteliais, resultando em atrofia e perda da barreira mecânica de proteção da mucosa bucal.

Porém, nem todos os agentes quimioterápicos são igualmente estomatotóxicos ou causam os mesmos efeitos nos tecidos bucais. Os antimetabólicos ${ }^{61}$, como o metotrexate, que inibem a síntese do DNA, tendem a produzir mucosite. Efeito similar é observado com os agentes alquilantes, como o 5-fluorouracil. Antibióticos, como a adriamicina, podem causar problemas diretos na boca ou efeitos colaterais, em conseqüência de seus efeitos sobre as glândulas salivares menores. Os alcalóides vegetais raramente causam desintegração direta da mucosa bucal, mas podem criar problemas bucais devido ao seu potencial neurotóxico ${ }^{61}$.

Os efeitos colaterais, geralmente, tendem a estar relacionados diretamente com a dose da droga administrada em determinado tempo. Provavelmente, o intervalo da administração da droga é mais importante do que a dose total da droga. Por exemplo, se uma determinada dose pode causar problemas bucais significativos, quando administrada em dose única, a mesma dose pode deixar de causar qualquer efeito colateral, se administrada em doses menores, num período de tempo mais prolongado ${ }^{61}$.

Entre as substâncias que podem causar mucosite bucal, usualmente utilizadas nos protocolos de tratamento para leucemia linfóide aguda, podemos destacar ${ }^{30,57,61}$ : 
- agentes alquilantes quando usados em altas doses, como bussulfano, ciclofosfamida, carboplatina, cisplatina, ifosfamida, mecloretamina, melfalam, procarbazina e tiotepa;

- $\quad$ antraciclinas: daunorrubicina, doxorrubicina (especialmente com regimes de infusão contínua), epirrubicina. Estes medicamentos inibem o crescimento celular e diminuem o índice mitótico. Em doses habituais inibem a síntese do RNA e em doses elevadas a do DNA.

- antimetabólitos: citarabina (em altas doses), fluorouracil, fludarabina, gemcitabina, metotrexate, 6-mercaptopurina, 6-tioguanina. Entre as drogas citadas o metotrexate consiste em um antagonista do ácido fólico, impedindo a conversão a ácido folínico por inibição enzimática. O ácido fólico é um elemento essencial no processo de síntese celular. Em doses elevadas o metotexate apresenta diversos efeitos colaterais e os sinais cíclicos de sua intoxicação incluem ardor, dor na mucosa bucal, mucosite moderada/severa, eritema cutâneo, diarréia, áreas de hiperpigmentação e/ou descamação em regiões previamente com eritema.

- antibióticos anti-tumorais: actinomicina D, bleomicina, mitomicina.

Mesmo com a diversidade de drogas utilizadas no tratamento da LLA, as principais drogas associadas a mucosite bucal incluem o metrotrexato, a citarabina, a daunorrubicina e o fluorouracil ${ }^{29,30}$.

A toxicidade do tratamento para LLA na região gastrointestinal incluindo a boca no que se refere a mucosite de acordo com o National Cancer Institute pode ser subdividida $\mathrm{em}^{31}$ :

GRAU 0 - ausência de lesões; 
GRAU 1 (Leve) - eritema na mucosa com mínimos sintomas e dieta normal;

GRAU 2 (Moderada) - ulceração irregular ou pseudomembranas, mas o paciente consegue se alimentar com dieta alterada;

GRAU 3 (Grave) - presença de ulceração ou pseudomembranas, sangramento ao mínimo trauma, dolorosa e o paciente não consegue comer ou beber;

GRAU 4 (Inaceitável) - necrose tecidual, significativo sangramento espontâneo e o paciente requer suporte parenteral ou enteral.

\subsubsection{Tratamento da mucosite bucal}

Em geral, as mucosites bucais devem ser tratadas conservativamente para futuramente evitar irritação na mucosa e células remanescentes, as quais são responsáveis pela regeneração do epitélio. O controle da placa e higiene bucal devem ser mantidos com escovação dentária cuidadosa ${ }^{55,61}$. O potencial benéfico dos bochechos com clorexidina podem controlar o nível de placa, gengivite, reduzir o risco de cárie e candidose orofaríngea, ao invés de uma ação direta sobre a mucosite. O paciente deve ser orientado a manter uma dieta suave, evitando substâncias irritantes como temperos, tabaco ou álcool. A nutrição deve ser mantida ${ }^{55}$.

O tratamento da mucosite bucal consiste em terapias paliativas que visam a melhora dos sintomas, aliviando a sensibilidade dolorosa do paciente e prevenindo a ocorrência de infecções secundárias. Nos centros especializados no tratamento de leucemia linfóide aguda, diferentes terapêuticas têm sido utilizadas, destacando-se recentemente, os tratamentos baseados no uso do laser de baixa potência, considerado uma terapia não invasiva que promove o alívio da dor, reduz a gravidade das lesões bucais, pois acelera seu processo de cicatrização, sendo dessa forma, bem aceito pelos pacientes, inclusive pelas crianças ${ }^{53}$. 
Para BIRON et al. ${ }^{7} 2000$, as únicas formas de tratamento e prevenção da mucosite e seus sintomas consistem na eliminação profilática de focos agudos ou potenciais de infecção prévios a quimio/radioterapia, bochechos com soro fisiológico e estratégias para controle da dor com uso de analgesia, devendo levar em consideração cada fase de desenvolvimento das lesões e seus mecanismos físiopatológicos conhecidos até o momento.

COSTA et al. ${ }^{15}$, em 2003, avaliaram um protocolo de prevenção bucal em 14 crianças de dois a dez anos com LLA que receberam quimioterapia por um período de seis semanas, as crianças foram divididas em dois grupos (grupo experimental e controle), o grupo experimental realizava diariamente duas escovações (manhã e tarde) supervisionadas por parentes e/ou dentista e bochechos com solução não alcoólica de clorexidina a $0,12 \%$, o grupo controle diferia na utilização de uma solução placebo para o bochecho. Como resultado apenas uma criança do grupo experimental e cinco do controle desenvolveram mucosite bucal entre o segundo e quarto dia após a administração intravenosa da quimioterapia (metotrexate) e a maior freqüência foi na mucosa labial e bucal. 
3 PROPOSIÇÃO 



\section{PROPOSIÇÃO}

A partir da análise retrospectiva de prontuários clínicos de pacientes oncológicos pediátricos com leucemia linfóide aguda, submetidos ao tratamento no Setor de Oncologia Pediátrica do Hospital Infantil Darcy Vargas, na cidade de São Paulo, SP, propôs-se:

- verificar a prevalência de mucosite bucal nestes pacientes;

- correlacionar a mucosite bucal com o gênero, a idade, a contagem de leucócitos iniciais obtida antes do tratamento quimioterápico e o protocolo de tratamento;

- avaliar a freqüência de mucosite bucal em relação aos grupos de risco de recaída nos diferentes protocolos de tratamento a que foram submetidos os pacientes;

- investigar a ocorrência de outras lesões bucais nestes pacientes associadas ou não à mucosite bucal. 
4 MATERIAL E MÉTODOS 



\section{MATERIAL E MÉTODOS}

\subsection{População de Estudo e Seleção da Amostra}

A população de estudo foi constituída por 169 pacientes oncológicos pediátricos submetidos ao tratamento ou em tratamento de leucemia linfóide aguda no Setor de Oncologia Pediátrica do Hospital Infantil Darcy Vargas, na cidade de São Paulo, com idade entre 5 meses e 18 anos, no período compreendido entre 1994 a 2005. Foram utilizados os seguintes critérios de inclusão:

- $\quad$ pacientes portadores de Leucemia Linfóide Aguda diagnosticados e tratados desde o início no Hospital Infantil Darcy Vargas, SP;

- pacientes com prontuários clínicos completos e acessíveis a coleta de dados;

- $\quad$ pacientes submetidos aos protocolos de tratamento: Grupo Brasileiro de Tratamento de Leucemia da Infantil (GBTLI) 93, GBTLI 99, Grupo Europeu Berlim-Frankfurt-Munique (BFM) 95 e BFM 02. 
Foram excluídos desta pesquisa todos os prontuários que apresentaram:

- $\quad$ pacientes portadores de doenças não contempladas no projeto de pesquisa;

- $\quad$ pacientes submetidos a outros protocolos de tratamento;

- $\quad$ pacientes com início do tratamento em outro centro especializado;

- $\quad$ pacientes que foram a óbito e o prontuário estava inacessível.

\subsection{Registro dos Dados Clínicos}

As informações referentes aos pacientes foram registradas em formulário próprio, específico (Figura 2) para essa finalidade e obtidas a partir dos prontuários pertencentes ao banco de dados do Serviço de Arquivo Médico do Hospital Infantil Darcy Vargas.

Estes registros incluíram a identificação e os dados demográficos dos pacientes (idade, gênero, naturalidade), informações relativas à história clínica e evolução do paciente com leucemia linfóide aguda (diagnóstico da doença, tempo de duração da doença, grupo de risco, outra doença sistêmica simultânea), tratamento (medicação usada ou em uso, protocolo de tratamento e fase da quimioterapia). A ocorrência de mucosite, bem como a contagem de leucócitos e a presença de outras lesões bucais também foram registradas.

O tratamento quimioterápico dos pacientes oncológicos pediátricos com LLA do Hospital Infantil Darcy Vargas, SP, nos últimos 11 anos foi baseado nos protocolos do Grupo Brasileiro para Tratamento de Leucemia Infantil (GBTLI) de 1993, 1999 e nos protocolos do ALL-Berlim-Frankfurt-Munique (ALL-BFM) de 1995 e 2002.

Estes protocolos dividem os pacientes em grupos de risco como pode ser observado nas Figuras 3, 4, 5, 6, 7, 8, 9,10, 11,12,e 13. Por exemplo, de acordo com o protocolo do ALL-BFM 1995 temos a seguinte distribuição dos grupos de risco de recaída 
da LLA:

\section{Grupo de Baixo Risco:}

- células leucêmicas $<1000 / \mu \mathrm{l}$ no sangue periférico no Dia 8 após administração de 7 dias de Prednisona ;

- $\quad$ leucócitos $<20.000 / \mu l$ e idade $\geq 1<6$ anos;

- $\quad$ remissão completa no Dia 33 (Medula-M1);

- $\quad$ ausência de translocação t(9;22) respectivamente recombinação BCR/ABL;

- ausência de translocação t(4;11) respectivamente recombinação MLL/AF4;

- $\quad$ ausência de imunologia T;

Todos os seis critérios devem estar preenchidos.

\section{Grupo de Médio Risco:}

- células leucêmicas $<1000 / \mu l$ no sangue periférico no Dia 8 após administração de 7 dias de Prednisona ;

- $\quad$ remissão completa no Dia 33 (Medula-M1);

- $\quad$ ausência de translocação t(9;22) respectivamente recombinação BCR/ABL;

- $\quad$ ausência de translocação t(4;11) respectivamente recombinação MLL/AF4.

Todos os quatro critérios devem estar preenchidos, além disso, pelo menos um dos que se seguem:

- $\quad$ leucócitos $\geq 20.000 / \mu$;

- $\quad$ idade $<1$ ano;

- $\quad$ idade $\geq 6$ anos. 


\section{Grupo de Alto Risco:}

- $\quad \geq 1000$ células leucêmicas/ $\mu$ l no sangue periférico no dia 8 (=PrednisonaPR);

- $\quad$ ausência de remissão completa no dia 33;

- $\quad$ translocação t(9;22) respectivamente recombinação BCR/ABL;

- $\quad$ translocação t(4;11) respectivamente recombinação MLL/AF4;

Cada critério sozinho qualifica para o grupo de alto risco independente de idade e leucócitos.

\subsection{Análise estatística}

Todos os dados clínicos obtidos foram armazenados em planilha do excel sendo as correlações entre a ocorrência da mucosite bucal e o gênero, a idade, a leucometria inicial e os protocolos de tratamento obtidos pelo teste do qui-quadrado e análise de regressão logística multivariada com nível de significância de 5\%.

\subsection{Comitê de Ética}

Este estudo foi conduzido após aprovação pela Comissão de Ética Médica do Hospital Infantil Darcy Vargas na cidade de São Paulo, SP, no dia 12 de outubro de 2004, protocolo $n^{0} 39 / 04$. 
FIGURA 2: Formulário específico para coleta de informações clínicas

\section{FORMULÁRIO PARA COLETA DE DADOS CLÍNICOS}

FATORES DE RISCO PARA MUCOSITE BUCAL EM PACIENTES COM LEUCEMIA LINFÓIDE AGUDA SUBMETIDOS A DIFERENTES PROTOCOLOS DE TRATAMENTO

C.D. Suzana Luzia Coelho Figliolia; C.D. Ana Rosa Maurício;

Profa. Dra. Denise Tostes Oliveira

1. Nome do paciente:

2. Matrícula: Data de nascimento:

3. Naturalidade:

4.Endereço:

5. Gênero: $\square$ Feminino $\square$ Masculino

6. Idade:

7. Data do ínicio do tratamento oncológico:

8. Mucosite Bucal: $\square$ Não $\square$ Sim

9. Fase do Tratamento em que ocorreu a mucosite: $\square$ indução

$\square$ consolidação/intensificação

$\square$ re-indução

$\square$ manutenção

10. Protocolo usado: $\square$ GBTLI93 $\square$ GBTLI99 $\square$ ALL-BFM $95 \square$ ALL-BFM 02 11. Medicações em uso no momento:

12. Exames Laboratoriais:

Hematócrito:

Hemoglobina:

Leucócitos:

Plaquetas:

Outros:

13. Lesões bucais: $\square$ Não $\square$ Sim Qual:

14. Doenças sistêmicas:

15. Recaída da doença: $\square$ Não $\square$ Sim

16. Transplante de Medula Óssea: $\square$ Não $\square$ Sim

17. Evolução: $\square$ vivo com LLA $\square$ vivo sem LLA

$\square$ Morte por LLA $\square$ Morte por outras causas 
42 Material e Métodos 


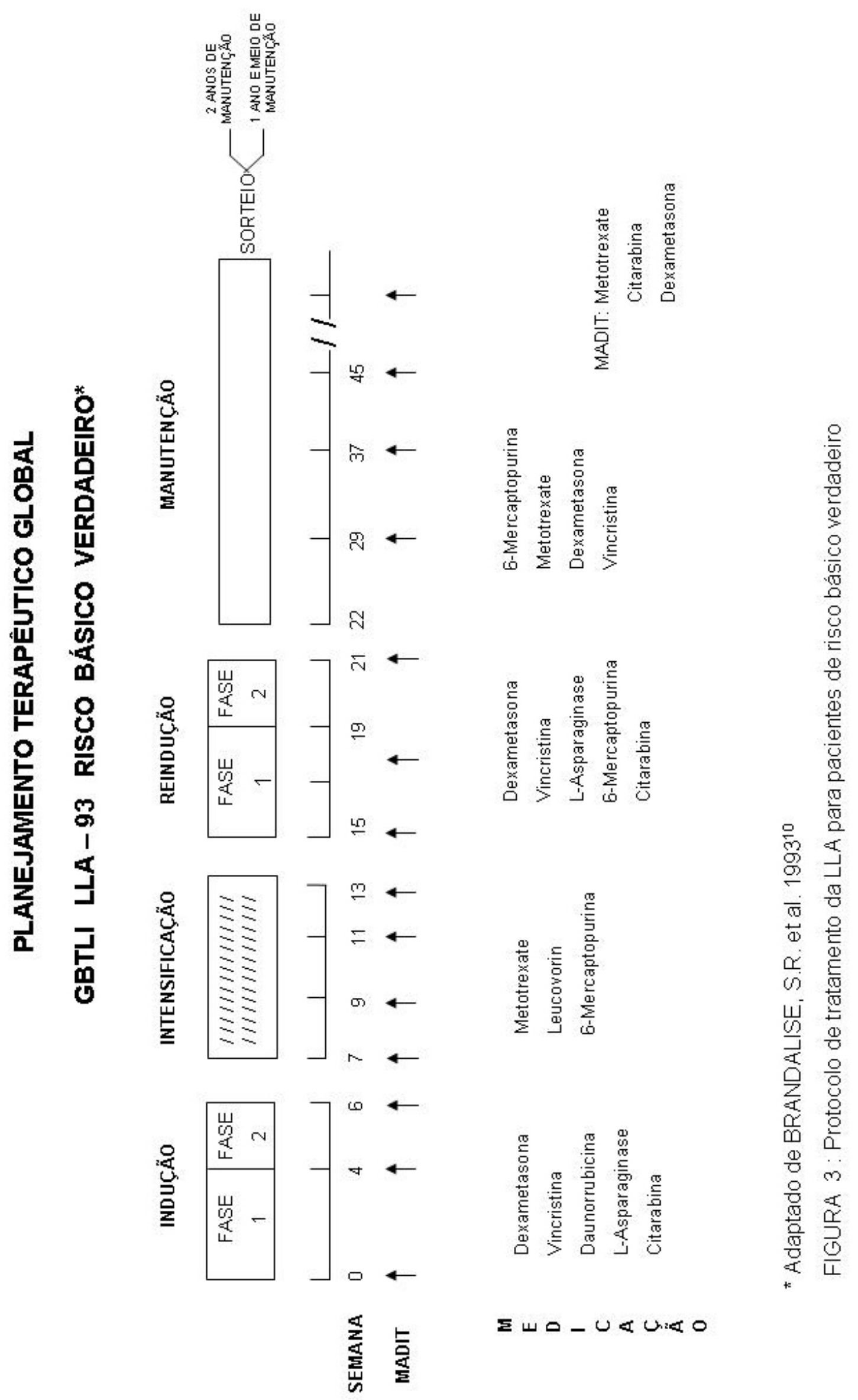


44 Material e Métodos 


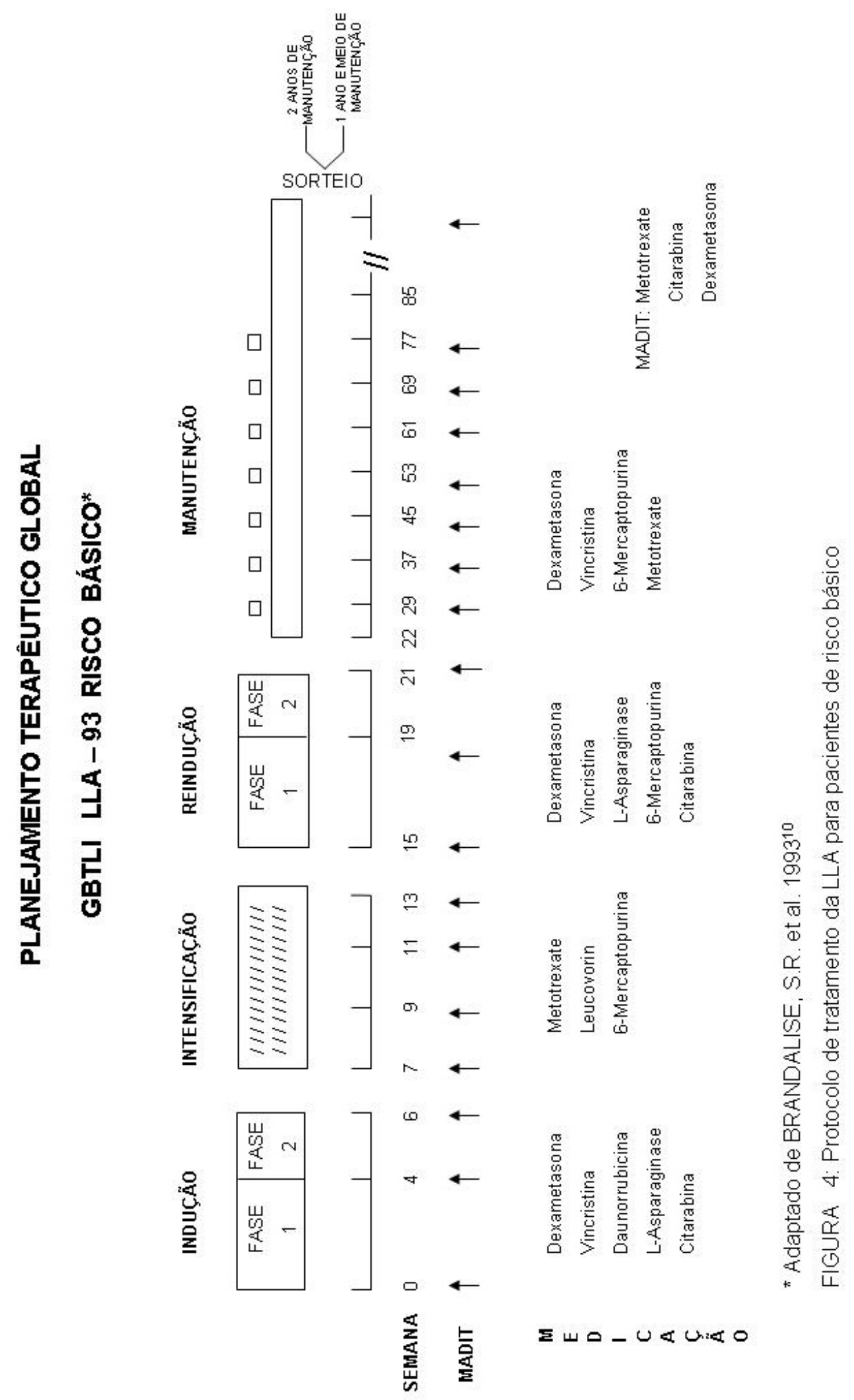


46 Material e Métodos 


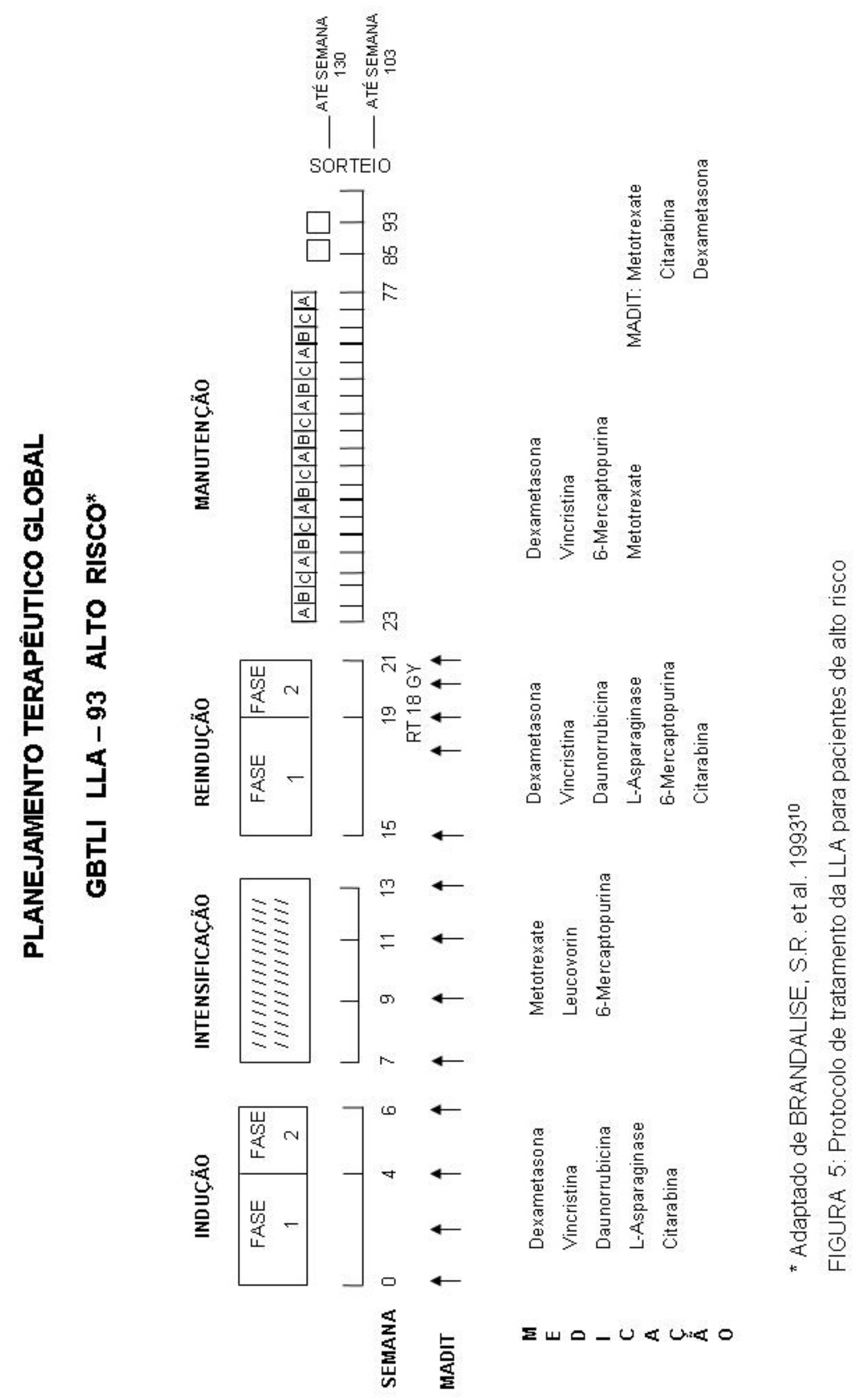


48 Material e Métodos 


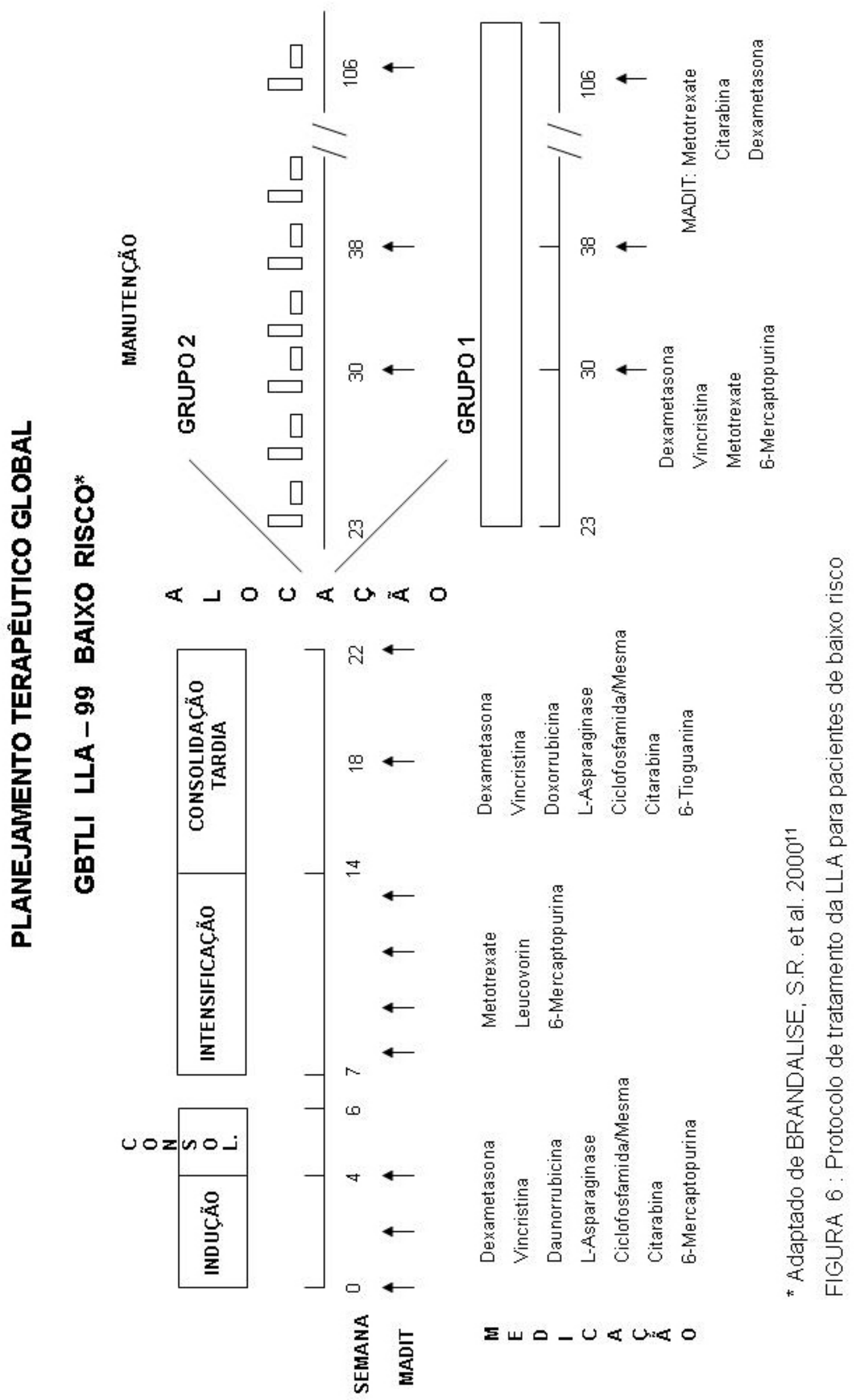




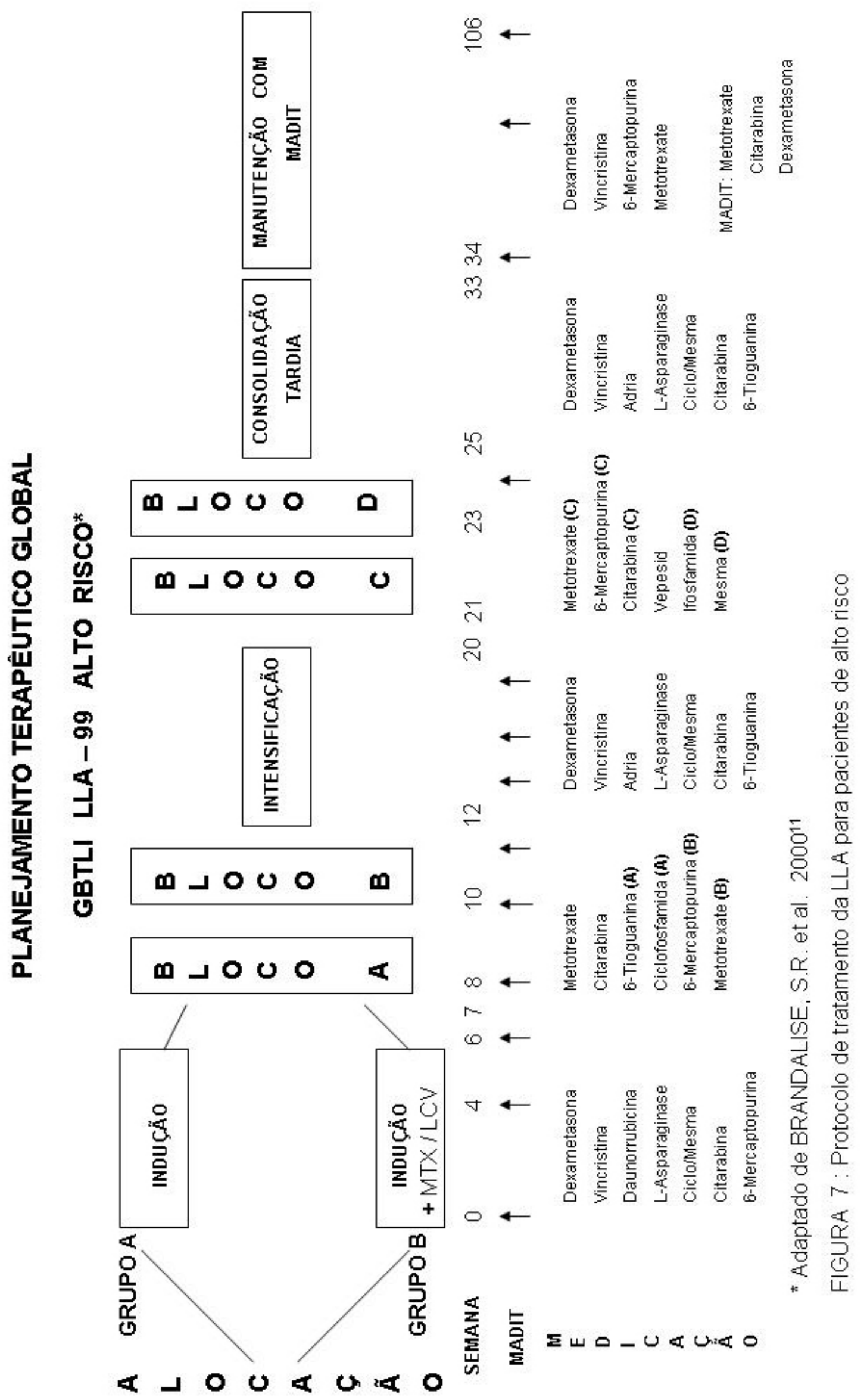


52 Material e Métodos 


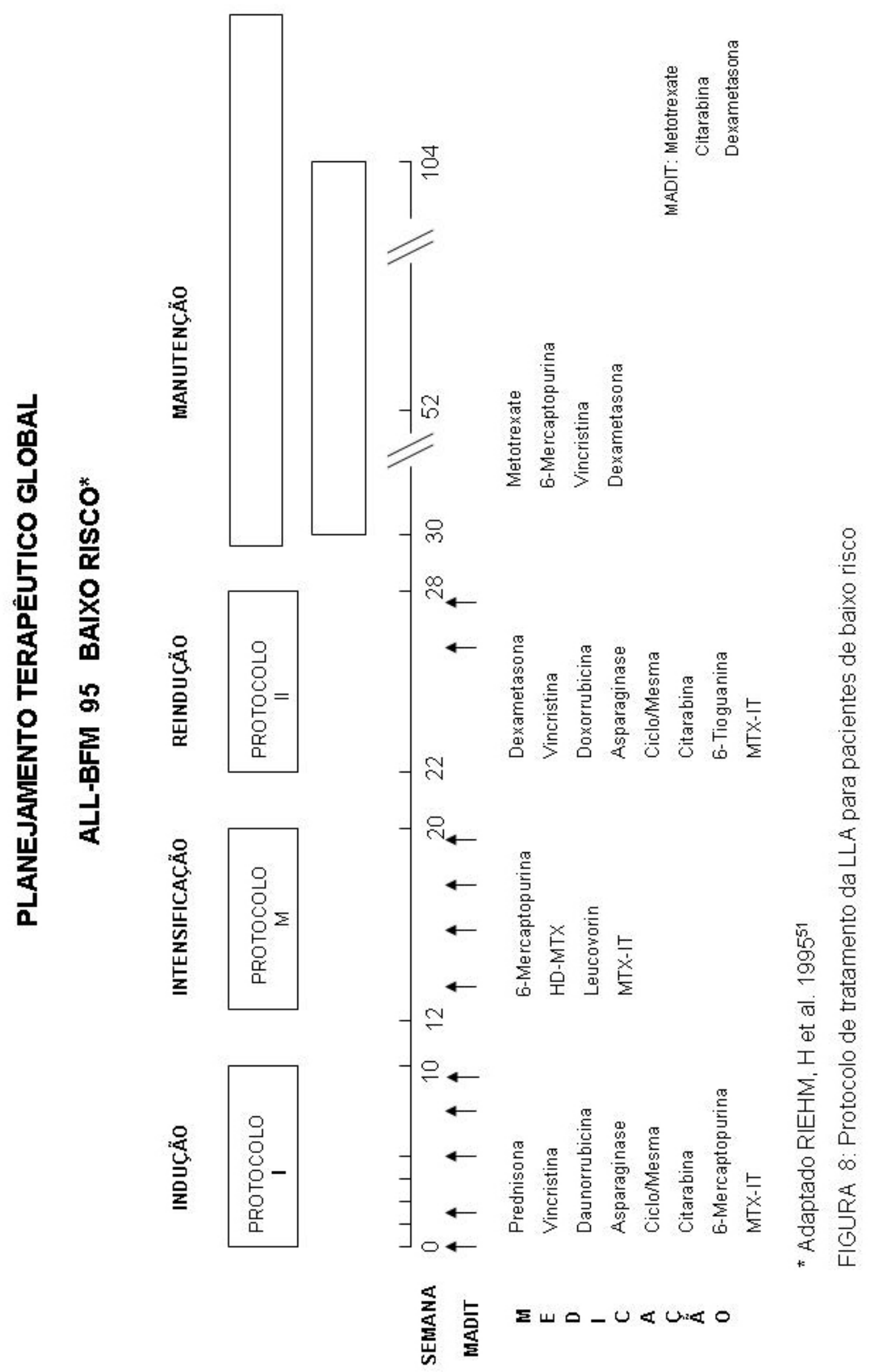


54 Material e Métodos 


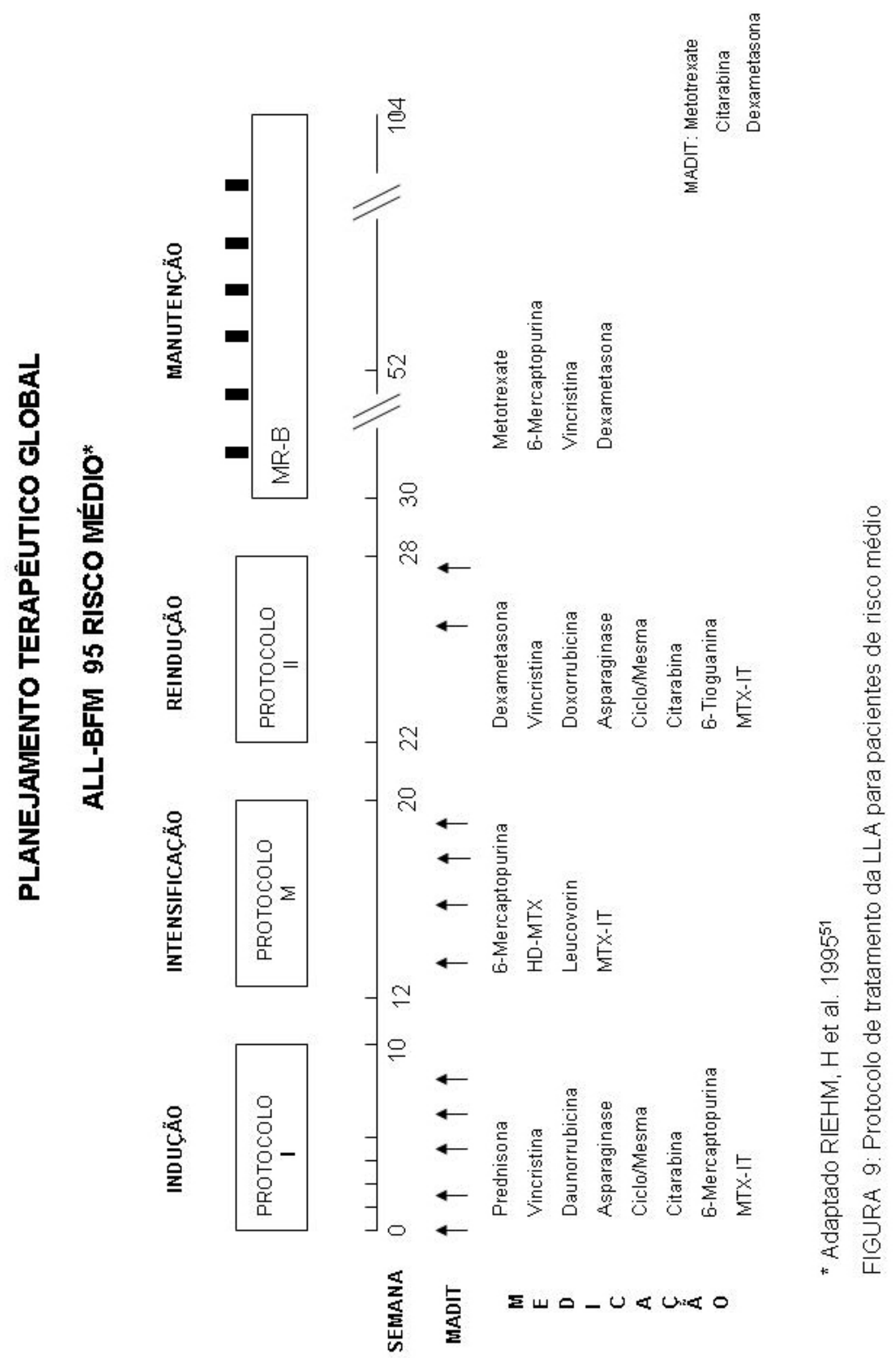


56 Material e Métodos 


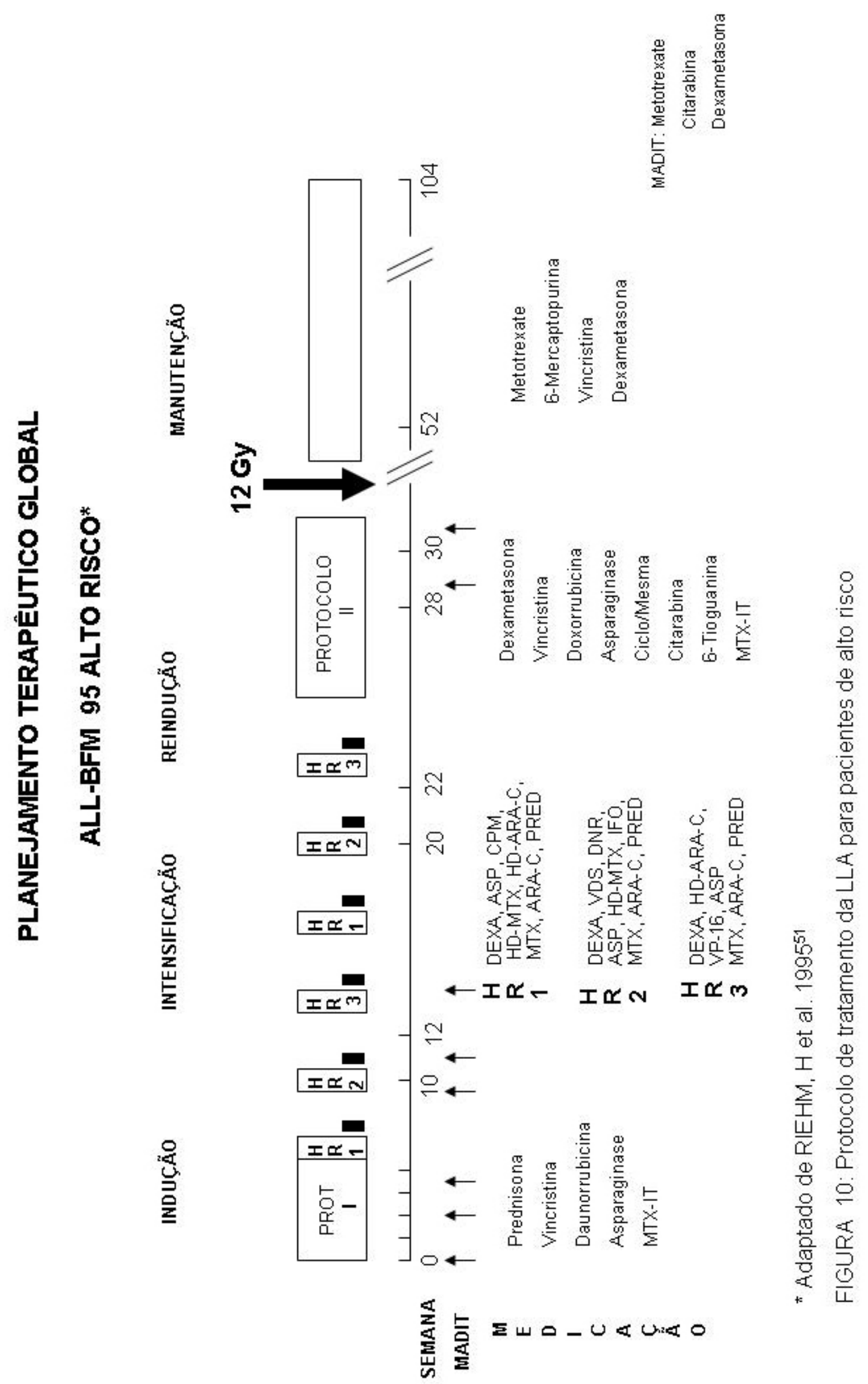




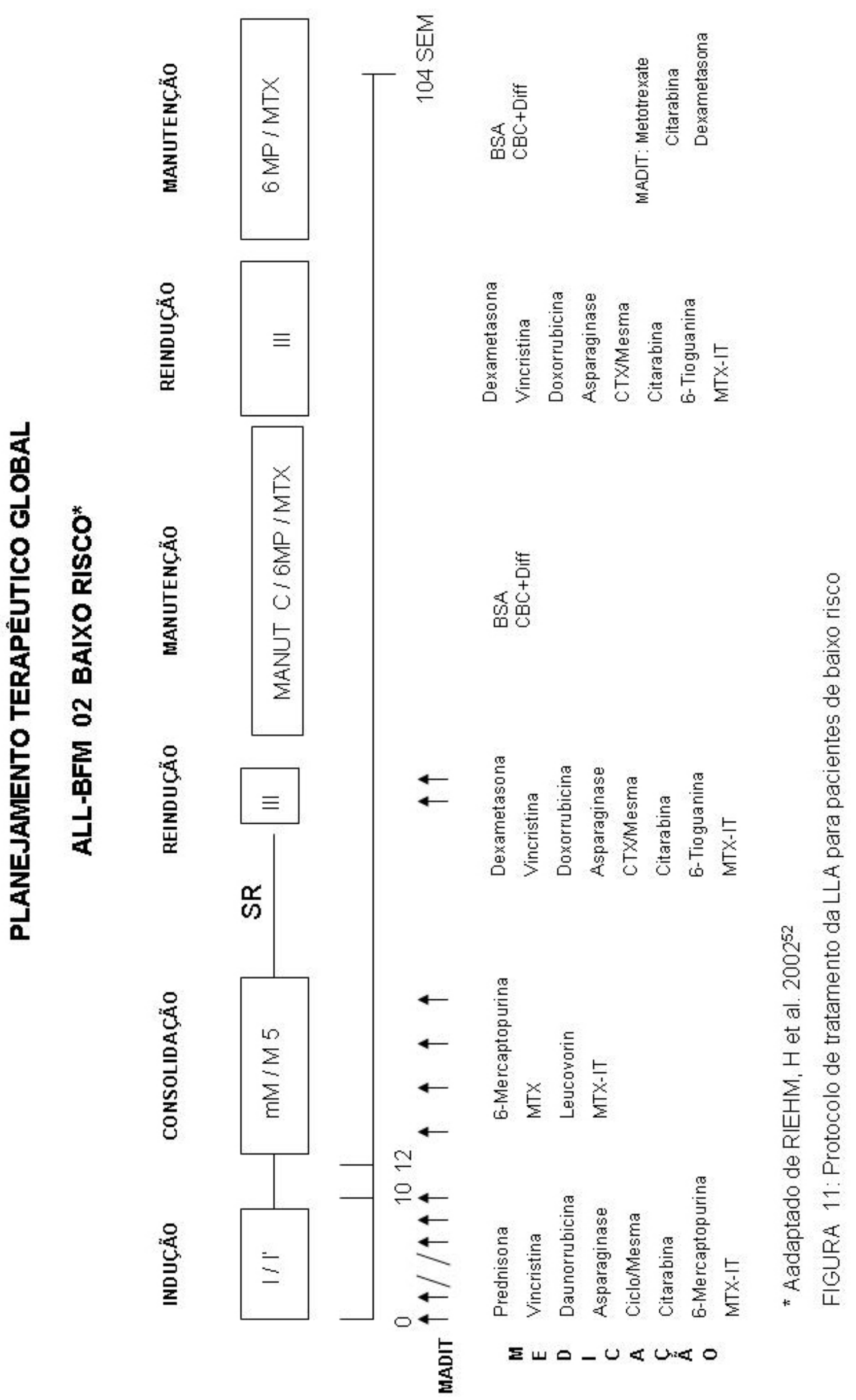


60 Material e Métodos 


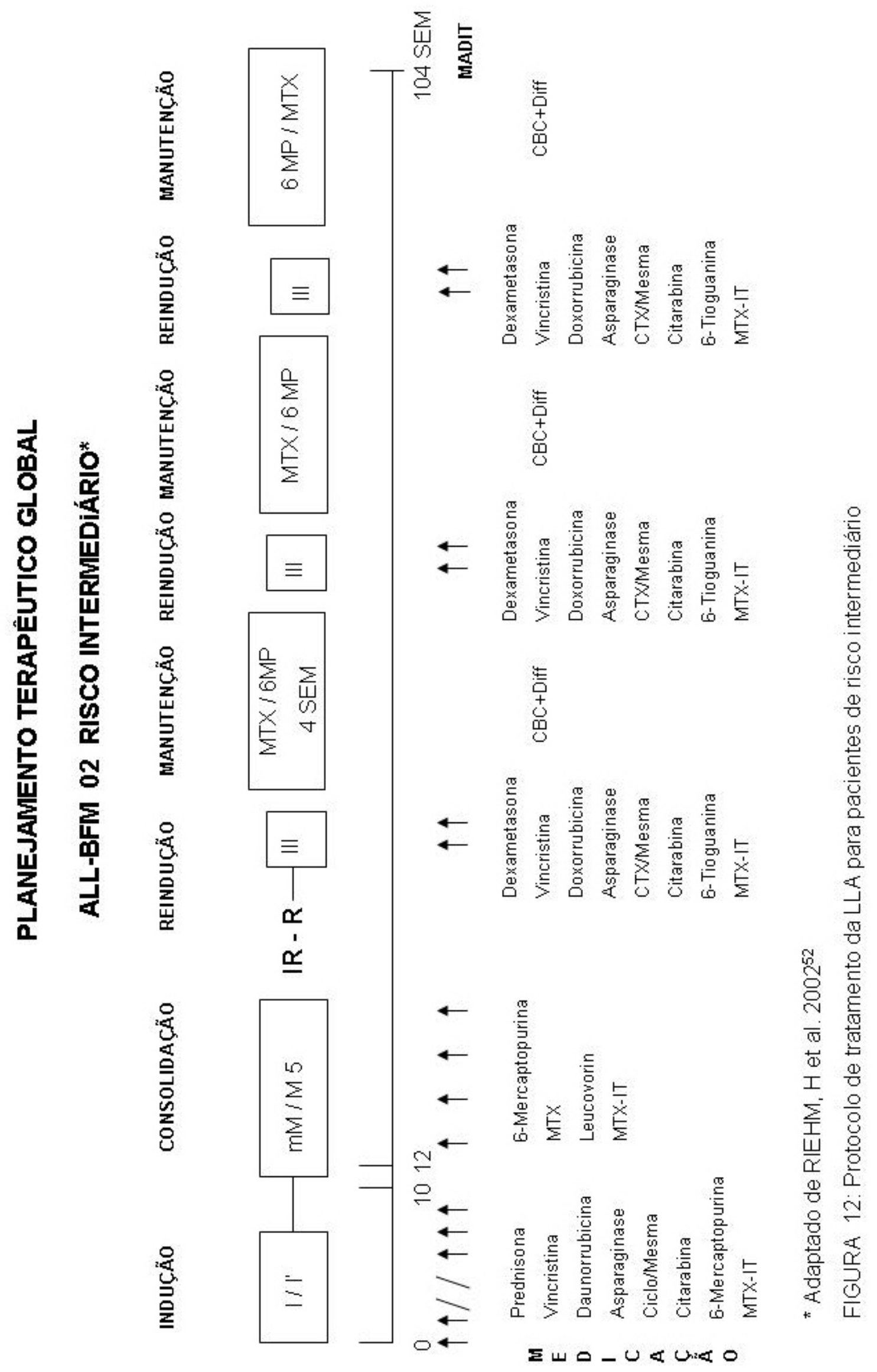


62 Material e Métodos 


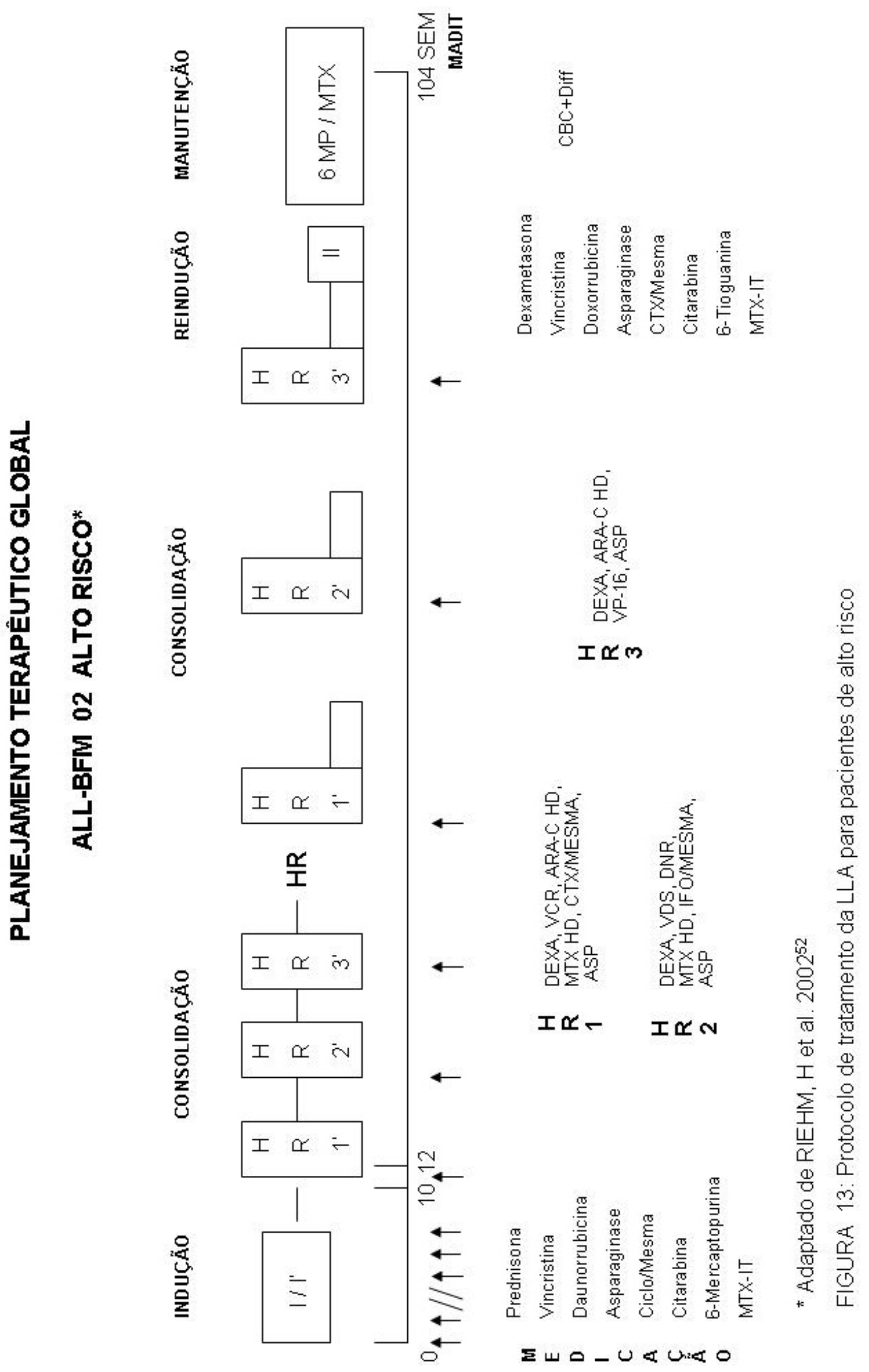


64 Material e Métodos 
5 RESULTADOS 


\section{RESULTADOS}

\subsection{Casuística}

O levantamento retrospectivo de 169 pacientes com leucemia linfóide aguda (LLA) tratados no Hospital Infantil Darcy Vargas em São Paulo, no período de 1994 a 2005, mostrou uma freqüência de 77 pacientes (46\%) que desenvolveram mucosite bucal em algum momento do tratamento como pode ser visualizado na Tabela 1 . Destes 77 pacientes, $24(31,1 \%)$ apresentaram mais de uma manifestação de mucosite bucal durante o tratamento da LLA. Apenas seis pacientes $(3,6 \%)$ com LLA foram submetidos ao transplante de medula óssea e destes dois foram a óbito.

TABELA 1 - Distribuição percentual da ocorrência de mucosite bucal em pacientes oncológicos pediátricos com leucemia linfóide aguda. Hospital Infantil Darcy Vargas, São Paulo, 1994 a 2005.

\begin{tabular}{ccc}
\hline \hline MUCOSITE BUCAL & N & \% \\
\hline SIM & 77 & 46 \\
NÃO & 92 & 54 \\
\hline TOTAL & $\mathbf{1 6 9}$ & $\mathbf{1 0 0}$ \\
\hline \hline
\end{tabular}

$\mathrm{N}=$ número de pacientes. 
A análise dos dados demográficos relativos aos 169 pacientes oncológicos pediátricos revelou uma maior ocorrência de LLA no gênero masculino $(59,2 \%)$, enquanto o gênero feminino constituía $40,8 \%$ da amostra (Tabela 2).

A idade mínima obtida na época do diagnóstico da neoplasia maligna foi de cinco meses e a idade máxima de 18 anos. A maioria dos pacientes oncológicos pediátricos $(76 \%)$ manifestaram a LLA precocemente na vida com idade inferior ou igual a nove anos (Tabela 2), e aproximadamente $50 \%$ destas estavam na faixa etária entre dois e cinco anos de idade.

A contagem inicial de leucócitos variou de 100 a $400.000 \mathrm{~mm}^{3}$ em nossa amostra sendo que houve uma distribuição eqüitativa entre os pacientes com 100 a 9300 leucócitos $/ \mathrm{mm}^{3}$ e aqueles com 9400 a 400.000 leucócitos $/ \mathrm{mm}^{3}$ (Tabela 2).

TABELA 2 - Distribuição percentual dos pacientes oncológicos pediátricos com LLA em relação ao gênero, idade e número iniciais de leucócitos $/ \mathrm{mm}^{3}$. Hospital Infantil Darcy Vargas, São Paulo, 1994 a 2005.

\begin{tabular}{llcc}
\hline & \multicolumn{2}{c}{ LEUCEMIA LINFÓIDE AGUDA } & \\
\cline { 2 - 3 } VARIAVÉIS & & $\mathbf{N}$ & $\%$ \\
\hline Gênero & Masculino & 100 & 59,2 \\
& Feminino & 69 & 40,8 \\
Idade & $\leq 9$ anos & 128 & 76,0 \\
& $\geq 10-\leq 18$ anos & 41 & 24,0 \\
Leucócitos $/ \mathrm{mm}^{3}$ & $100-9.300$ & 82 & 48,5 \\
& $9.400-400.000$ & 82 & 48,5 \\
& Não informado & 5 & 3,0 \\
\hline TOTAL & & 169 & 100 \\
\hline
\end{tabular}

$\mathrm{N}=$ número de pacientes 
A evolução clínica dos pacientes oncológicos pediátricos com LLA de acordo com o protocolo de tratamento a que foram submetidos pode ser observada na Tabela 3.

Nota-se que a maior freqüência de óbitos foi observada, principalmente, no protocolo de tratamento ALL-BFM-95 como pode ser visualizado na Tabela 3.

Dos 65 pacientes oncológicos pediátricos submetidos ao tratamento de LLA no Hospital Infantil Darcy Vargas em São Paulo, de acordo com o protocolo GBTLI 93, dois foram considerados perdidos de vista devido à transferência para continuação do tratamento em outro centro especializado por conveniência (residiam em outro estado ou cidade), três pacientes foram a óbito pela LLA e dois pacientes morreram por outras causas como pode ser visualizado na Tabela 3.

Entre os 58 pacientes oncológicos pediátricos também submetidos ao protocolo GBTLI 93 que estão vivos e fora do tratamento para LLA, 29 pacientes (50\%) podem ser considerados curados da doença e 29 pacientes (50\%) estão em proservação a menos de cinco anos (Tabela 3).

Com relação aos pacientes portadores de LLA submetidos ao protocolo de tratamento ALL-BFM 95, um foi transferido durante o tratamento e 28 pacientes permanecem em tratamento. Dos 74 pacientes submetidos ao protocolo ALL-BFM 95, 32 estão vivos e fora de tratamento, porém permanecem em proservação a menos de cinco anos, 13 pacientes foram a óbito por causa da LLA sendo que destes, 23\% apresentaram recaída da doença (Tabela 3).

Entre os 26 pacientes tratados de LLA pelo protocolo GBTLI 99, dois foram considerados perdidos de vista, 20 pacientes estão vivos e fora de tratamento, mas em proservação por um período inferior a três anos, um foi a óbito devido a outras causas e três pacientes estão vivos e em tratamento sendo que, um destes apresentou recaída da LLA durante a fase de manutenção. 
Os quatro pacientes oncológicos pediátricos que iniciaram o tratamento para LLA no Hospital Infantil Darcy Vargas submetidos ao protocolo de tratamento ALLBFM 02 permanecem vivos com a doença e em tratamento (Tabela 3).

Os pacientes foram considerados perdidos de vista quando estavam fora de tratamento e não retornaram para controle ou quando em tratamento de leucemia linfóide aguda foram transferidos para outros centros especializados.

TABELA 3 - Evolução clínica dos pacientes oncológicos pediátricos com leucemia linfóide aguda de acordo com protocolos de tratamento (GBTLI 93, ALL-BFM 95, GBTLI 99 e ALL-BFM 2002) a que foram submetidos. Hospital Infantil Darcy Vargas, São Paulo, 1994 a 2005.

\section{LEUCEMIA LINFÓIDE AGUDA}

PROTOCOLOS DE TRATAMENTO

\begin{tabular}{lcccc}
\hline EVOLUÇÃO & $\begin{array}{l}\text { GBTLI-93 } \\
\text { (N) }\end{array}$ & ALL-BFM-95 & GBTLI-99 & ALL-BFM-02 \\
\hline Morte por LLA & 3 & 13 & $(\mathrm{~N})$ & $(\mathrm{N})$ \\
$\begin{array}{l}\text { Morte por outras } \\
\text { causas }\end{array}$ & 2 & 0 & 0 & 0 \\
$\begin{array}{l}\text { Vivo com LLA } \\
\text { (em tratamento) }\end{array}$ & 0 & 28 & 0 \\
$\begin{array}{l}\text { Vivo sem LLA } \\
\text { (fora de tratamento) }\end{array}$ & 58 & 32 & 3 & 4 \\
$\begin{array}{l}\text { Perdido de vista } \\
\text { TOTAL }\end{array}$ & 2 & 1 & 20 & 0 \\
\hline $\begin{array}{l}\text { N = número de pacientes; GBTLI: Grupo Brasileiro de Tratamento da Leucemia Infantil } \\
\text { ALL-BFM: Acute lymphoblastic leukemia - Berlim-Frankfurt-Munique; }\end{array}$ \\
$\begin{array}{l}\text { LLA = Leucemia linfóide aguda } \\
65\end{array}$
\end{tabular}




\subsection{Associação da mucosite bucal com os fatores de risco para sua ocorrência em pacientes com LLA}

Ao avaliarmos a ocorrência de mucosite bucal em relação ao gênero notou-se uma maior freqüência no gênero feminino (54\%) se comparado ao gênero masculino (40\%) como pode ser visualizado na Tabela 4. Entretanto, a associação da mucosite bucal com o gênero não foi estatisticamente significativa $(p=0,08)$.

TABELA 4 - Correlação entre a ocorrência da mucosite bucal e o gênero dos pacientes oncológicos pediátricos com leucemia linfóide aguda. Hospital Infantil Darcy Vargas, São Paulo, 1994 a 2005.

MUCOSITE BUCAL

\begin{tabular}{ccccccccc}
\cline { 3 - 5 } & & \multicolumn{2}{c}{ SIM } & \multicolumn{2}{c}{ NÃO } & & \\
\cline { 3 - 6 } & & $\mathrm{N}$ & $\%$ & $\mathrm{~N}$ & $\%$ & TOTAL & $\boldsymbol{p}$ \\
\hline \multirow{2}{*}{ GÊNERO } & Masculino & 40 & 40,0 & 60 & 60,0 & 100 & \\
& Feminino & 37 & 54,0 & 32 & 46,0 & 69 & 0,08
\end{tabular}

$\mathrm{N}=$ número de pacientes;

$p=$ valor de $p$ obtido pelo teste do qui-quadrado com nível de significância de $5 \%$

Em relação à idade, uma maior freqüência de mucosite bucal nos pacientes com idade menor ou igual a nove anos foi observada (Tabela 5) se comparada aos pacientes com idade entre 10 e 18 anos, entretanto, esta diferença não foi estatisticamente significativa $(p=0,33)$.

Ao analisarmos a Tabela 6 podemos verificar que a freqüência de mucosite bucal para os pacientes com leucometria na faixa de $9.400-400.0001$ ucócitos $/ \mathrm{mm}^{3}$ foi maior quando comparado àqueles com leucometria na faixa de 100 - 
9.300leucócitos $/ \mathrm{mm}^{3}$, porém sem significância estatística. Em cinco pacientes, a leucometria inicial não foi encontrada no prontuário.

TABELA 5 - Correlação entre a ocorrência da mucosite bucal e a idade dos pacientes oncológicos pediátricos com leucemia linfóide aguda. Hospital Infantil Darcy Vargas, São Paulo, 1994 a 2005.

\begin{tabular}{|c|c|c|c|c|c|c|c|}
\hline & & & & & & & \\
\hline & & \multicolumn{6}{|c|}{ MUCOSITE BUCAL } \\
\hline & & \multicolumn{2}{|c|}{ SIM } & \multicolumn{2}{|c|}{ NÃO } & \multirow[b]{2}{*}{ TOTAL } & \multirow[b]{2}{*}{$p$} \\
\hline & & $\mathrm{N}$ & $\%$ & $\mathrm{~N}$ & $\%$ & & \\
\hline \multirow[t]{2}{*}{ IDADE } & $\leq 9$ anos & 61 & 48,0 & 67 & 52,0 & 100 & \multirow[b]{2}{*}{0,33} \\
\hline & $\geq 10-\leq 18$ anos & 16 & 39,0 & 25 & 61,0 & 69 & \\
\hline
\end{tabular}

$\mathrm{N}=$ número de pacientes;

$p=$ valor de $p$ obtido pelo teste do qui-quadrado com nível de significância de 5\%

TABELA 6 - Correlação entre a ocorrência da mucosite bucal e o número de leucócitos iniciais dos pacientes oncológicos pediátricos com leucemia linfóide aguda. Hospital Infantil Darcy Vargas, São Paulo, 1994 a 2005.

\begin{tabular}{|c|c|c|c|c|c|c|c|}
\hline & & \multicolumn{6}{|c|}{ MUCOSITE BUCAL } \\
\hline & & \multicolumn{2}{|c|}{ SIM } & \multicolumn{2}{|c|}{ NÃO } & \multirow[b]{2}{*}{ TOTAL } & \multirow[b]{2}{*}{$p$} \\
\hline & & $\mathrm{N}$ & $\%$ & $\mathrm{~N}$ & $\%$ & & \\
\hline LEUCÓCITOS & $100-9.300$ & 34 & 41,0 & 48 & 59,0 & 82 & \\
\hline \multirow[t]{2}{*}{$\left(\mathrm{mm}^{3}\right)$} & $9.400-400.000$ & 41 & 50,0 & 41 & 50,0 & 82 & 0,34 \\
\hline & Não informado & 4 & 80,0 & 1 & 20,0 & 5 & \\
\hline
\end{tabular}

$\mathrm{N}=$ número de pacientes;

$p=$ valor de $p$ obtido pelo teste do qui-quadrado com nível de significância de 5\% 
A distribuição da ocorrência de mucosite bucal nos pacientes com LLA de acordo com o protocolo de tratamento adotado pelo Hospital Darcy Vargas, São Paulo, no período de 1994 a 2005 pode ser observado na Tabela 7.

A maioria dos pacientes foi submetida ao protocolo de tratamento de leucemia linfóide aguda ALL-Berlim-Frankfurt-Munique (ALL-BFM) de 1995, sendo que 56,8\% destes desenvolveram mucosite bucal.

A reduzida amostra dos pacientes tratados pelo protocolo ALL-BFM de 2002 não permitiu uma análise consistente da ocorrência de mucosite bucal.

Nota-se ainda, que no grupo de pacientes submetidos ao protocolo de tratamento do Grupo Brasileiro para Tratamento de Leucemia Infantil de 1993 e 99, a ausência da ocorrência de mucosite bucal foi freqüentemente observada (Tabela 7).

Ao correlacionarmos a ocorrência da mucosite bucal entre os protocolos de tratamento utilizados pelos pacientes oncológicos pediátricos com leucemia linfóide aguda (GTBLI-93, GTBLI-99 e ALL-BFM-95) pelo teste do qui-quadrado obtivemos uma diferença estatisticamente significativa $(p=0,012)$. Deve ser ressaltado que os pacientes tratados pelo protocolo ALL-BFM de 2002 foram excluídos desta análise. Este resultado confirma que a freqüência de mucosite bucal nos pacientes submetidos ao protocolo de tratamento ALL-BFM de 1995 foi maior quando comparada aos pacientes tratados pelos protocolos GTBLI-93 e GTBLI-99 (Tabela 7). 
TABELA 7 - Distribuição percentual da ocorrência de mucosite bucal em relação aos protocolos de tratamento (GBTLI 93, ALL-BFM 95, GBTLI 99 e ALLBFM 2002) utilizados pelos pacientes oncológicos pediátricos com leucemia linfóide aguda. Hospital Infantil Darcy Vargas, São Paulo, 1994 a 2005.

\begin{tabular}{cccccc} 
& \multicolumn{5}{c}{ MUCOSITE BUCAL } \\
\cline { 2 - 5 } & \multicolumn{3}{c}{ SIM } & NOTAL \\
\cline { 2 - 5 } PROTOCOLOS & $\mathrm{N}$ & $\%$ & $\mathrm{~N}$ & $\%$ & \\
\hline GBTLI 93 & 20 & 30,8 & 45 & 69,2 & 65 \\
ALL-BFM 95 & 42 & 56,8 & 32 & 43,2 & 74 \\
GBTLI 99 & 12 & 46,2 & 14 & 53,8 & 26 \\
ALL-BFM 2002 & 3 & 75,0 & 1 & 25,0 & 4 \\
\hline \hline
\end{tabular}

$\mathrm{N}$ = número de pacientes; GBTLI: Grupo Brasileiro de Tratamento da Leucemia Infantil ALL-BFM: Acute lymphoblastic leukemia - Berlim-Frankfurt-Munique

Quando se utilizou o teste de regressão logística multivariada para análise comparativa de todas as variáveis juntas (gênero, idade, faixa de leucócitos e protocolos de tratamento) a única variável que apresentou diferença estatística significativa $(p=0,009)$ com relação à ocorrência de mucosite bucal foi o protocolo ALL-BFM 95 como pode ser visualizado na Tabela 8.

Esta mesma correlação foi obtida quando se realizou o teste do quiquadrado para cada variável como já descrito anteriormente. Deve ser ressaltado, entretanto, que o protocolo de tratamento ALL-BFM 2002 foi excluído das análises estatísticas por apresentar número reduzido de pacientes oncológicos pediátricos. 
TABELA 8 - Correlação da ocorrência de mucosite bucal com o gênero, a idade, a leucometria inicial e os protocolos de tratamento (GBTLI 93, ALLBFM 95, GBTLI 99 e ALL-BFM 2002) utilizados pelos pacientes oncológicos pediátricos com leucemia linfóide aguda de acordo com a análise de regressão logística multivariada. Hospital Infantil Darcy Vargas, São Paulo, 1994 a 2005.

MUCOSITE BUCAL

\begin{tabular}{|c|c|c|c|c|c|c|c|}
\hline & \multirow{2}{*}{\multicolumn{2}{|c|}{ SIM }} & & & & \\
\hline & & & & \multicolumn{2}{|c|}{ NÃO } & \multirow[b]{2}{*}{ TOTAL } & \multirow[b]{2}{*}{$p$} \\
\hline \multicolumn{2}{|l|}{ VARIÁVEIS } & $\mathrm{N}$ & $\%$ & $\mathrm{~N}$ & $\%$ & & \\
\hline \multirow[t]{2}{*}{ Gênero } & Masculino & 40 & 40,0 & 60 & 60,0 & 100 & 0,201 \\
\hline & Feminino & 37 & 54,0 & 32 & 46,0 & 69 & \\
\hline \multirow[t]{2}{*}{ Idade } & $\leq 9$ anos & 61 & 48,0 & 67 & 52,0 & 128 & 0,697 \\
\hline & $\geq 10-\leq 18$ anos & 16 & 39,0 & 25 & 61,0 & 41 & \\
\hline \multirow{3}{*}{$\begin{array}{l}\text { Leucócitos } \\
\left(\mathrm{mm}^{3}\right)\end{array}$} & $100-9.300$ & 34 & 41,0 & 48 & 59,0 & 82 & 0,560 \\
\hline & $9.400-400.000$ & 41 & 50,0 & 41 & 50,0 & 82 & \\
\hline & Não informado & 4 & 80,0 & 1 & 20,0 & 5 & \\
\hline \multirow{3}{*}{$\begin{array}{l}\text { Protocolos de } \\
\text { tratamento }\end{array}$} & GBTLI 93 & 20 & 30,8 & 45 & 69,2 & 65 & \\
\hline & ALL-BFM 95 & 42 & 56,8 & 32 & 43,2 & 74 & 0,009 \\
\hline & GBTLI 99 & 12 & 46,2 & 14 & 53,8 & 26 & 0,206 \\
\hline $\begin{array}{l}\mathrm{N}=\text { número de } \mathrm{p} \\
\mathrm{ALL}-\mathrm{BFM} \text { : Acu } \\
p=\text { valor de } p \\
\text { significânc }\end{array}$ & $\begin{array}{l}\text { acientes; GBTLI: } \\
\text { te lymphoblastic le } \\
\text { obtido pelo teste } \\
\text { ia de } 5 \%\end{array}$ & Pu & $\begin{array}{l}\text { sileiro } \\
\text { erlim } \\
\text { são } 1\end{array}$ & Trat & $\begin{array}{l}\text { nto da } \\
\text { Muniq } \\
\text { tivar }\end{array}$ & eucem & Infantil \\
\hline
\end{tabular}




\subsection{Frequência da mucosite bucal em relação aos grupos de risco dos diferentes protocolos de tratamento para LLA}

Quando a ocorrência de mucosite bucal nos pacientes oncológicos pediátricos com LLA, submetidos ao protocolo de tratamento GTBLI 93, foi distribuída de acordo com os grupos de risco, observou-se que 36\% dos pacientes de risco básico (RB) e $23,3 \%$ dos de alto risco (AR) apresentavam história clínica de mucosite como pode ser observado na Tabela 9.

Dos 20 pacientes que apresentaram mucosite bucal, quatro $(20 \%)$ ocorreram na fase de indução, quatro (20\%) na fase de intensificação, três $(15 \%)$ na fase de reindução e oito (40\%) ocorreram na fase de manutenção do protocolo de tratamento GTBLI 93. Desses 20 pacientes apenas um apresentou mais de uma manifestação de mucosite bucal sendo uma manifestação na fase de indução e a outra na fase de manutenção.

TABELA 9 - Distribuição percentual da ocorrência de mucosite bucal em pacientes oncológicos pediátricos com leucemia linfóide aguda em relação aos grupos de risco do protocolo de tratamento GBLTI 93. Hospital Infantil Darcy Vargas, São Paulo, 1994 a 2005.

\begin{tabular}{|c|c|c|c|c|c|}
\hline \multirow[b]{3}{*}{ GRUPOS } & \multicolumn{5}{|c|}{ MUCOSITE BUCAL } \\
\hline & \multicolumn{2}{|c|}{ SIM } & \multicolumn{2}{|c|}{ NÃO } & \multirow{2}{*}{ TOTAL } \\
\hline & $\mathrm{N}$ & $\%$ & $\mathrm{~N}$ & $\%$ & \\
\hline BRV & 2 & 50,0 & 2 & 50,0 & 4 \\
\hline $\mathrm{BR}$ & 11 & 36,0 & 20 & 64,0 & 31 \\
\hline $\mathrm{AR}$ & 7 & 23,3 & 23 & 76,7 & 30 \\
\hline
\end{tabular}


Ao analisarmos os pacientes com LLA submetidos ao protocolo de tratamento ALL-BFM de 1995, uma maior freqüência de mucosite bucal $(64,1 \%)$ foi verificado no grupo de médio risco (Tabela 10). Dos 42 pacientes que desenvolveram mucosite bucal 16 pacientes manifestaram duas ocorrências clínicas da lesão $(38,1 \%)$ e dois pacientes desenvolveram três ocorrências $(7,1 \%)$, sendo que a maioria destas manifestações ocorreu na fase de indução do protocolo de tratamento ALL-BFM de 1995.

TABELA 10 - Distribuição percentual da ocorrência de mucosite bucal em pacientes oncológicos pediátricos com leucemia linfóide aguda em relação aos grupos de risco do protocolo de tratamento ALL-BFM 95. Hospital Infantil Darcy Vargas, São Paulo, 1994 a 2005.

\begin{tabular}{|c|c|c|c|c|c|}
\hline \multirow[b]{3}{*}{ GRUPOS } & \multicolumn{5}{|c|}{ MUCOSITE BUCAL } \\
\hline & \multicolumn{2}{|c|}{ SIM } & \multicolumn{2}{|c|}{ NÃO } & \multirow{2}{*}{ TOTAL } \\
\hline & $\mathrm{N}$ & $\%$ & $\mathrm{~N}$ & $\%$ & \\
\hline $\mathrm{BR}$ & 9 & 43,0 & 12 & 57,0 & 21 \\
\hline MR & 25 & 64,1 & 14 & 35,9 & 39 \\
\hline AR & 8 & 57,1 & 6 & 42,9 & 14 \\
\hline
\end{tabular}

$\mathrm{N}$ = número de pacientes; BR: paciente de baixo risco no protocolo ALL-BFM 95; MR: paciente de médio risco no protocolo ALL-BFM 95; AR: paciente de alto risco no protocolo ALL-BFM 95; ALL-BFM: Acute lymphoblastic leukemia - BerlimFrankfurt-Munique

Dos 26 pacientes submetidos ao protocolo de tratamento GTBLI 99, um total de $14(53, \%)$ não manifestaram a mucosite bucal. Quando analisamos a ocorrência de mucosite bucal nos pacientes oncológicos pediátricos com LLA, de acordo com os grupos de risco do protocolo de tratamento GTBLI 99, observa-se uma maior freqüência nos pacientes de alto risco (AR) como pode ser observado na Tabela 11. 
Dos 12 pacientes que apresentaram mucosite bucal, cinco apresentaram mais de uma ocorrência da lesão sendo detectadas nas fases de indução, intensificação, consolidação tardia e manutenção do protocolo de tratamento GTBLI-99.

TABELA 11 - Distribuição percentual da ocorrência de mucosite bucal em pacientes oncológicos pediátricos com leucemia linfóide aguda em relação aos grupos de risco do protocolo de tratamento GBLTI 99. Hospital Infantil Darcy Vargas, São Paulo, 1994 a 2005.

\begin{tabular}{cccccc} 
& \multicolumn{5}{c}{ MUCOSITE BUCAL } \\
\cline { 2 - 5 } & \multicolumn{3}{c}{ SIM } & TOTAL \\
\hline GRUPOS & $\mathrm{N}$ & $\%$ & $\mathrm{~N}$ & $\%$ & \\
\hline BR & 5 & 29,4 & 12 & 70,6 & 17 \\
AR & 7 & 77,8 & 2 & 22,2 & 9
\end{tabular}

$\mathrm{N}$ = número de pacientes; BR: paciente de baixo risco no protocolo GBTLI 99; AR: paciente de alto risco no protocolo GBTLI 99.

Com relação aos pacientes com LLA submetidos ao protocolo de tratamento ALL-BFM de 2002, devido ao número reduzido de pacientes na amostra como mostra a Tabela 12 torna-se difícil uma análise da freqüência de mucosite bucal entre os grupos de risco. 
TABELA 12 - Distribuição percentual da ocorrência de mucosite em pacientes oncológicos pediátricos com leucemia linfóide aguda em relação aos grupos de risco do protocolo de tratamento ALL-BFM 2002. Hospital Infantil Darcy Vargas, São Paulo, 1994 a 2005.

\begin{tabular}{cccccc} 
& \multicolumn{5}{c}{ MUCOSITE BUCAL } \\
\cline { 2 - 5 } & \multicolumn{3}{c}{ SIM } & \multicolumn{3}{c}{ NÃO } & TOTAL \\
\hline GRUPOS & $\mathrm{N}$ & $\%$ & $\mathrm{~N}$ & $\%$ & \\
\hline BR & 1 & 100 & 0 & 0,0 & 1 \\
MR & 1 & 100 & 0 & 0,0 & 1 \\
AR & 1 & 50,0 & 1 & 50,0 & 2 \\
\hline \hline
\end{tabular}

$\mathrm{N}$ = número de pacientes; BR: paciente de baixo risco no protocolo ALL-BFM 2002; MR: paciente de médio risco no protocolo ALL-BFM 2002; AR: paciente de alto risco no protocolo ALL-BFM 2002; ALL-BFM: Acute lymphoblastic leukemia - BerlimFrankfurt-Munique

A ocorrência típica da mucosite bucal nos pacientes com LLA submetidos a quimioterapia no Hospital Infantil Darcy Vargas pode ser observada nas Figuras 14A e 14B.

As lesões são inicialmente caracterizadas por áreas eritematosas que evoluem para úlceras geralmente afetando mucosa não queratinizada (Figura 14A). As lesões apresentam intensa sintomatologia dolorosa causando desconforto ao paciente.

Pacientes com manifestações graves de mucosite bucal, devido a direta estomatotoxicidade das drogas quimioterápicas, com extensas áreas ulceradas como ilustrado na Figura 14B afetando diferentes regiões da mucosa bucal e/ou gástrica, requerem um maior período de hospitalização devido a impossibilidade de alimentação via oral e do risco de infecções sistêmicas. 
80 Resultados 

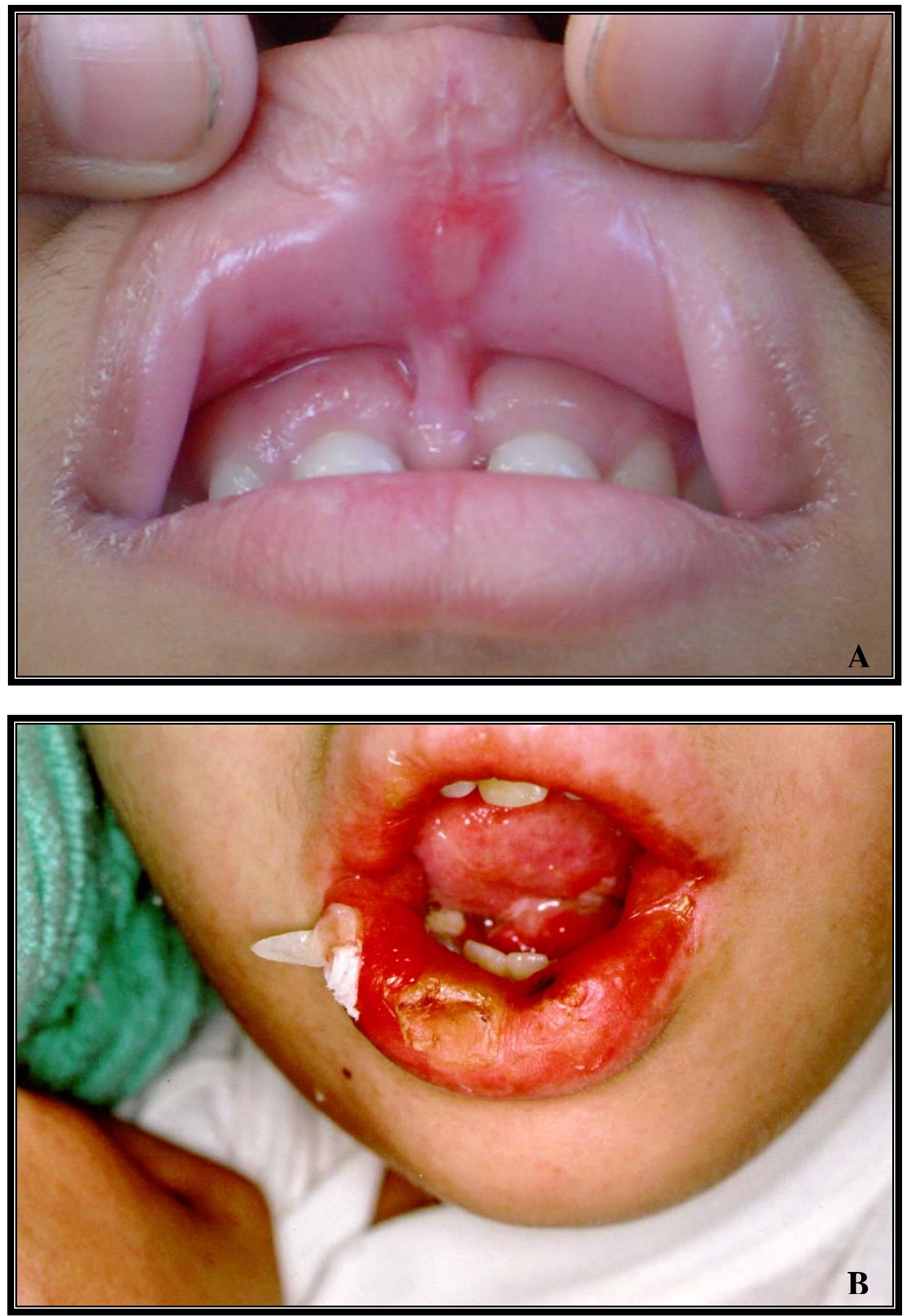

FIGURA 14 - Manifestação da mucosite bucal com lesões discretas no lábio (A) e lesões mais graves (B) nos pacientes com leucemia linfóide aguda em tratamento no Hospital Infantil Darcy Vargas em São Paulo. 
82 Resultados 


\subsection{Freqüência de mucosite bucal em relação a outras doenças sistêmicas e/ou locais apresentadas pelos pacientes com LLA}

A análise dos prontuários permitiu verificar que alguns pacientes apresentaram também doenças sistêmicas sendo as principais descritas na Tabela 13. Muitas destas alterações clínicas se desenvolveram durante o tratamento da LLA como conseqüência direta da terapia imunossupressora.

Entre os pacientes oncológicos pediátricos de nossa amostra seis pacientes eram portadores de Síndrome de Down e um paciente apresentou Anemia Falciforme. Em relação as doenças desenvolvidas em decorrência da terapia antineoplásica, quatro pacientes desenvolveram diabetes pelo Elspar (Asparaginase), dois tiveram cardiopatia, quatro crianças apresentaram Hepatite medicamentosa e duas crianças manifestaram trombose venosa.

Algumas doenças infecciosas com manifestações sistêmicas como a bronquite, o herpes zoster, a pneumonia, a sinusite e a varicela também ocorreram nos pacientes oncológicos pediátricos do Hospital Infantil Darcy Vargas, durante o tratamento da leucemia linfóide aguda, muitas destas, simultaneamente, a ocorrência de mucosite bucal (Tabela 13).

Especificamente na boca, o herpes labial foi a infecção viral mais freqüente em nossa amostra manifestando-se em 23 pacientes sendo que 13 destes também apresentaram mucosite bucal. Outras infecções bucais de origem fúngica como a queilite angular ou bacteriana como a actinomicose também foram registradas (Tabela 13). Aftas de origem traumática ocorreram em 14 pacientes com LLA como descrito na Tabela 13. 
TABELA 13 - Distribuição percentual da ocorrência de mucosite bucal em pacientes oncológicos pediátricos com leucemia linfóide aguda em relação a outras doenças sistêmicas e/ou bucais apresentadas pelo paciente. Hospital Infantil Darcy Vargas, São Paulo, 1994 a 2005.

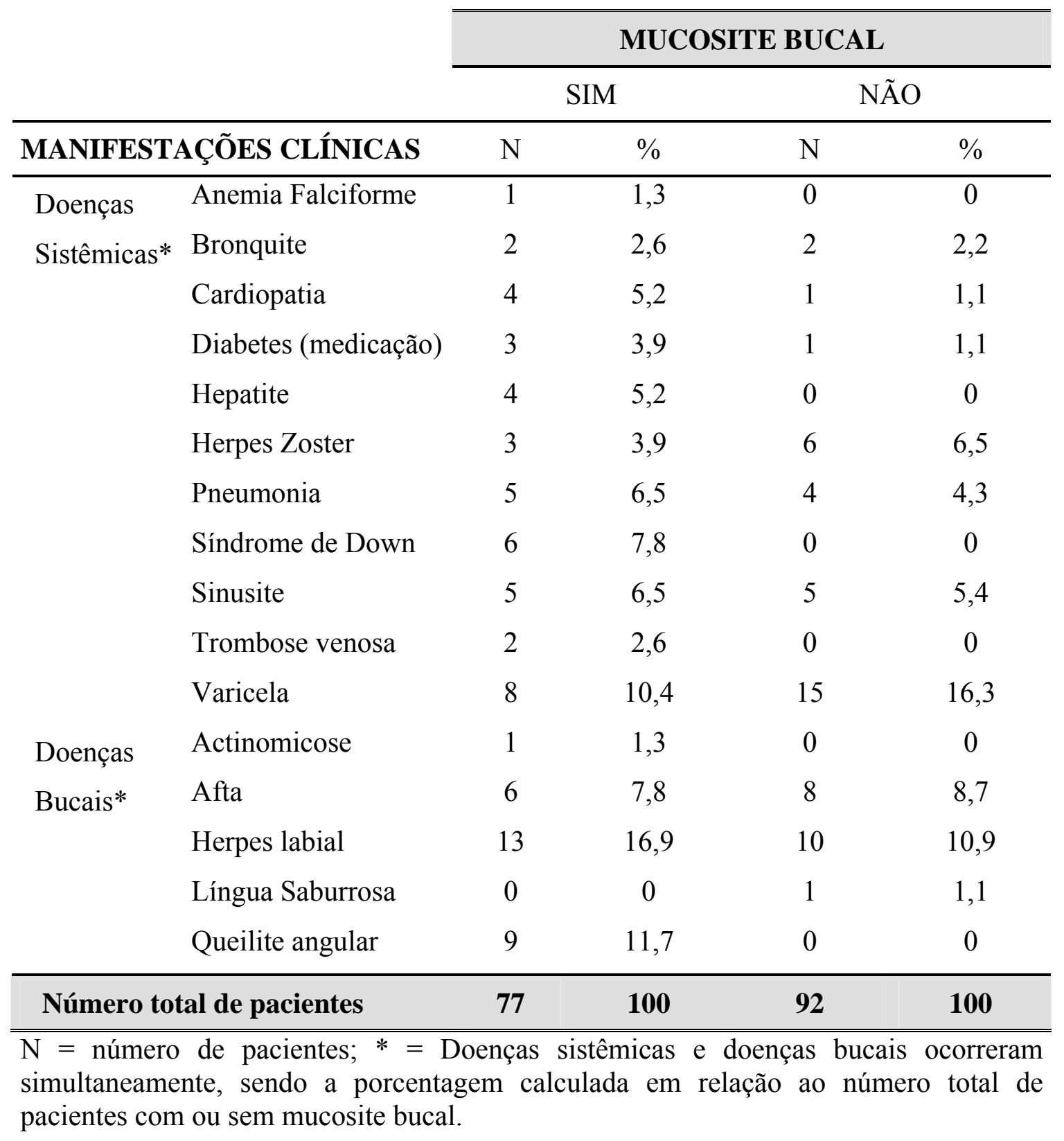


6 DISCUSSÃO 



\section{DISCUSSÃO}

A leucemia linfóide aguda permanece como uma importante causa de mortalidade infantil em todo o mundo. No Brasil de cada 10 a 15 casos de câncer na infância, quatro são de leucemia linfóide aguda ${ }^{39}$.

Durante o tratamento da LLA, devido à toxicidade das drogas quimioterápicas muitas intercorrências clínicas inclusive de origem infecciosas, vinculadas à intensidade da imunossupressão são esperadas. Entre os efeitos estomatotóxicos mais importantes associados com a LLA destaca-se a mucosite bucal e gastrointestinal. O termo mucosite bucal surgiu na década de 1980 sendo utilizado para descrever uma inflamação da mucosa bucal induzida pela quimioterapia e radioterapia, a qual representa uma entidade separada e distinta de outras lesões bucais patogênicas conhecidas como estomatites ${ }^{44}$.

Sabe-se que a mucosite bucal nos pacientes oncológicos pode ser causada diretamente pelas drogas quimioterápicas ${ }^{3,18,28,30,42,55,56}$, porém sua intensidade e extensão variam de paciente para paciente. Alguns fatores de risco como, por exemplo, a idade, o gênero e a leucometria inicial tem sido correlacionados com esta variabilidade na ocorrência da mucosite bucal nos pacientes pediátricos com LLA ${ }^{3,10,11,18,28,30,42,55,56}$.

A concepção inicial deste trabalho consistia no exame clínico para análise da prevalência de mucosite e outras lesões bucais em pacientes oncológicos pediátricos. 
Entretanto, em função da ocorrência de mucosite em aproximadamente $40 \%$ dos pacientes submetidos a quimioterapia ou radioterapia decidimos realizar inicialmente um estudo retrospectivo visando conhecer melhor a população a ser estudada. Para isto, procuramos o Setor de oncologia pediátrica do Hospital Infantil Darcy Vargas, em São Paulo, centro especializado no tratamento para LLA, para a obtenção dos dados referentes a mucosite bucal a partir da análise dos prontuários clínicos no período de 1994 a 2005. Posteriormente, verificamos que embora a mucosite bucal seja uma intercorrência clínica esperada durante o tratamento para LLA, tornou-se necessário investigar se sua ocorrência estava associada com os diferentes protocolos de tratamento quimioterápicos a que são submetidos os pacientes oncológicos pediátricos, o que se tornou um dos principais questionamentos a serem respondidos neste trabalho.

Em nossa casuística verificamos que dentre os 169 pacientes oncológicos pediátricos com leucemia linfóide aguda tratados ou em tratamento no Hospital Infantil Darcy Vargas no período de 1994 a 2005, houve uma maior freqüência da doença (Tabela 2) no gênero masculino (59,2\% dos pacientes) e em crianças abaixo de nove anos de idade (76\% dos pacientes) sendo que destas, em torno de 65\% estavam na faixa etária entre dois e cinco anos de idade. Estes resultados reforçam outros estudos da literatura $^{21,24,26,33,43}$ que descreveram a faixa etária entre dois e cinco anos como a de maior pico de incidência da LLA.

Em relação ao gênero, uma maior freqüência de LLA em meninos do que em meninas tem sido descrito ${ }^{4,19,43}$, confirmando os achados de nossa amostra onde $59,2 \%$ dos pacientes eram do gênero masculino (Tabela 2).

A leucometria inicial foi variável como pode ser visualizado na Tabela 2 sendo este um dos fatores a serem considerados na determinação do grupo de risco de recaída em alguns protocolos de tratamento para LLA como, por exemplo, no GBTLI 93. Neste 
protocolo $^{10}$, a idade do paciente e a contagem leucocitária ao diagnóstico representavam os fatores de risco mais importantes para a estratificação dos grupos de risco de recaída. Nesta época, outros fatores prognósticos pré-tratamento importantes como a imunofenotipagem, o índice de DNA e a citogenética ainda não eram rotineiramente, realizados na maioria dos serviços no Brasil ${ }^{11}$.

A partir do protocolo GBTLI 99, onde foram adotados os critérios de risco do National Cancer Institute para o diagnóstico da doença ${ }^{11}$, pela primeira vez foi considerado a resposta terapêutica do paciente avaliado em três momentos da terapia de indução (dias 7, 14 e 28) como critérios adicionais para definição de baixo risco de recaída. Assim sendo, neste protocolo de tratamento para $L_{L A}{ }^{11}$ os doentes de baixo risco são aqueles com idade acima de um ano e $\leq 9$ anos de idade e/ou com leucometria inicial inferior a 50.000/ $\mathrm{mm}^{3}$. Adicionalmente, os pacientes de baixo risco de recaída neste protocolo de tratamento ${ }^{11}$ eram aqueles que apresentam no sangue periférico do $7^{\circ}$ dia glóbulos brancos $<5000 / \mathrm{mm}^{3}$ e ausência de blastos no sangue periférico no $14^{\circ}$ dia da indução (ou entre $13^{\circ}$ e $15^{\circ}$ dias) mais medula M1/M2 no dia 14 (ou entre o $13^{\circ}$ e $15^{\circ}$ dias).

Uma determinação apurada do grupo de risco de recaída a qual o paciente com LLA pertence, possibilita uma abordagem terapêutica diferenciada, pois os grupos de maior risco são tratados com terapias mais intensas, cada vez mais eficazes, enquanto os grupos de baixo risco apresentam melhor sobrevida, podendo ser poupados dos efeitos deletérios da quimioterapia ${ }^{19,20,46}$.

Os índices de cura da LLA estão entre 70 e $80 \%^{23,39,42,46,47,49,63}$ e em nossa casuística ao analisarmos a evolução clínica dos pacientes verificamos que a porcentagem de óbitos nos últimos 11 anos foi de 13 pacientes submetidos ao protocolo de tratamento ALL-BFM 95 e 3 pacientes submetidos ao protocolo GBTLI 93. Como a 
maioria dos pacientes com LLA em nossa casuística ainda está em acompanhamento e terminaram o tratamento a menos de cinco anos, as taxas de cura não puderam ser estabelecidas. Apenas 29 pacientes (50\%) dos 58 pacientes com LLA submetidos ao protocolo GTBLI 93 que estão vivos e fora do tratamento podem ser considerados curados da doença (Tabela 3).

Recentemente, SWENSEN et al. ${ }^{63}$ realizaram uma análise da incidência e taxas de cura da LLA em diferentes países do mundo e constataram que a incidência da doença é duas a quatro vezes maior em países desenvolvidos do que nos países em desenvolvimento. Exemplificando, os autores verificaram uma incidência de LLA aproximadamente três vezes maior na Inglaterra do que no Kuwait, além de uma das maiores incidências do mundo de LLA na Costa Rica que, embora sendo um país não desenvolvido economicamente, apresenta-se bastante modernizado com relação a comportamentos sociais, incluindo educação e cultura.

As elevadas taxas de cura da LLA, em torno de 80\% nos países mais desenvolvidos, têm sido associadas, principalmente, ao progresso na introdução de novas drogas com protocolos terapêuticos adequados, a multidisciplinaridade nos cuidados com o paciente, a infraestrutura hospitalar adequada e ao suporte psicossocial e econômico às famílias dos pacientes ${ }^{63}$. Porém, estes bons resultados nas taxas de cura da LLA contrastam com as altas taxas de recidiva da doença, com o abandono do tratamento e com maiores índices de óbitos nos países pobres, incluindo as poucas estratégias para o combate de doenças infecciosas ${ }^{43,50}$.

O Brasil, mesmo sendo um país em desenvolvimento, tem conseguido bons índices de cura da LLA. Em Pernambuco, mais especificamente em Recife, por exemplo, PEDROSA; LINS, 2002, evoluíram de uma taxa de 29\% de cura de LLA nos anos 80 para $75 \%$ de cura na era atual. Segundo os autores ${ }^{43}$ o avanço do suporte 
hemoterápico, a utilização de fatores de crescimento de neutrófilos, o melhor controle da infecção e dos distúrbios metabólicos têm contribuído para esse sucesso. Confirmando a evolução dos tratamentos da LLA, que nas décadas passadas era considerada uma doença fatal $^{43}$, verificamos em nossa amostra, ao analisarmos a Tabela 3, que as taxas de óbito da doença nos últimos 11anos no Hospital Darcy Vargas, considerando-se apenas os pacientes fora de tratamento foi em torno de $14 \%$.

Quando analisamos a freqüência da mucosite bucal nos pacientes com LLA observamos que $46 \%$ destes manifestaram esta alteração em algum momento do tratamento quimioterápico. Esta freqüência esta próxima da ocorrência em torno de 40\% de mucosite bucal em pacientes com LLA descrita por alguns autores ${ }^{6,56,61}$.

O paciente com mucosite bucal grave (Figura 14) apresenta importantes problemas nutricionais o que aumenta, significativamente, a sensação de sofrimento e tristeza, bem como o tempo de hospitalização do mesmo. Adicionalmente, ocorre um aumento no custo do tratamento que neste caso torna-se associado à terapia opióide, dieta líquida suplementar, nutrição parenteral, internação, profilaxia ou controle de infecções secundárias ${ }^{17,28,31,58,59}$.

A idade do paciente tem sido descrita como um importante fator de risco para

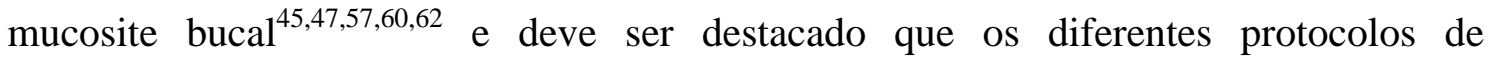
tratamento quimioterápico para LLA levam em consideração este fator na determinação do grupo de risco para recaída ${ }^{10,11,51}$.

Em nossa casuística uma maior freqüência de mucosite bucal foi detectada nos pacientes com idade igual ou menor que nove anos (48\% das crianças) quando comparado com os pacientes na faixa etária dos dez aos 18 anos de idade (39\% das crianças) e embora a diferença entre estes dois grupos não tenha sido estatisticamente significativa, ela pode ser comparada a outros estudos ${ }^{1,45,60}$ que descreveram uma maior 
prevalência de mucosite bucal em crianças menores de 12 anos de idade. Segundo alguns autores ${ }^{45,61}$ isto se justifica devido a atividade mitótica das células da mucosa bucal ser significativamente maior em crianças e jovens do que em indivíduos adultos tornando o epitélio mais susceptível a toxicidade das drogas quimioterápicas que afetam diretamente a proliferação celular, resultando em atrofia e perda da barreira mecânica de proteção da mucosa bucal .

Com relação ao gênero, observamos em nosso estudo uma maior freqüência de mucosite bucal entre os pacientes com LLA do gênero feminino (54\%) se comparado ao gênero masculino (40\%), entretanto, esta associação do gênero com a mucosite bucal não foi significativa estatisticamente. Um recente estudo de VOKURKA et al. ${ }^{65} 2006$ sugere que o gênero pode ter um importante papel como fator de risco independente e como fator preditivo para mucosite bucal em protocolos envolvendo altas doses quimioterápicas. Segundo os autores ${ }^{65}$ as mulheres parecem ser mais suscetíveis do que os homens a esta complicação pós-quimioterapia, entretanto, eles afirmam que outros estudos são necessários para uma melhor definição dos significativos fatores de risco para mucosite bucal, pois os fatores preditivos de maior risco para sua ocorrência são importantes do ponto de vista clínico tendo em vista os altos custos da administração de agentes preventivos.

Os pacientes oncológicos pediátricos com LLA que apresentaram leucometria inicial mais elevada (9400 a 400.000leucócitos/mm³) em nossa amostra, também demonstraram maior freqüência de mucosite bucal do que os pacientes com leucometria inicial menor, embora, estatisticamente sem significância (Tabela 6). A leucometria inicial elevada comumente reflete um maior risco de recaída da doença com conseqüente, pior prognóstico e os pacientes são submetidos a uma terapêutica para 
LLA mais agressiva ${ }^{10,11,51,52}$. Portanto, podemos concluir que em nossa amostra houve uma coerência entre a ocorrência da mucosite bucal e a leucometria inicial.

Como nossa pesquisa foi desenvolvida a partir de um estudo retrospectivo de 11 anos, durante esse período mais de um protocolo de tratamento para LLA, nacional ou internacional, foi utilizado no Hospital Darcy Vargas em São Paulo. Estes protocolos são baseados nas experiências dos protocolos anteriores e variam na medicação utilizada, na dosagem das mesmas, na forma de administração bem como no intervalo entre a infusão e o tempo de tratamento ${ }^{10,11,51,52}$.

No presente estudo foram analisados quatro protocolos de tratamento para LLA, sendo dois do grupo brasileiro de tratamento da leucemia infantil (GBTLI) de 1993 e 1999 e dois do grupo europeu Berlim-Frankfurt-Munique ALL-BFM de 1995 e de 2002. Na análise multivariada o protocolo de tratamento ALL-BFM 95, de acordo com as variáveis avaliadas neste estudo mostrou ser o fator mais significativo $(\mathrm{p}=0,009)$ para a ocorrência da mucosite bucal. Neste protocolo (ALL-BFM 95) as drogas quimioterápicas são administradas em maior número e mais intensamente na fase de indução (Figura 8,9,10) com duração de 64 dias em média nos grupos de baixo e médio risco de recaída e em torno de 36 dias no grupo de alto risco de recaída ${ }^{51}$.

A fase de indução de qualquer protocolo de tratamento para LLA tem por objetivo a obtenção da remissão completa da doença, ou seja, atingir $<5 \%$ de blastos na medula óssea e restaurar a hematopoiese normal com desaparecimento de toda a sintomatologia clínica associada com a doença ${ }^{32,34,42,43,51}$. Podemos então inferir que a maior associação da mucosite bucal com o protocolo ALL-BFM 95 se comparado aos protocolos GBTLI 93 e GBTLI 99, provavelmente está refletindo uma maior toxicidade sistêmica das drogas quimioterápicas utilizadas durante o tratamento da LLA como descrito por outros ${ }^{30,40}$. 
Estes resultados também concordam com os de WARDLEY et al. ${ }^{66}$, em 2000, ao correlacionarem, em 429 pacientes oncológicos com tumores sólidos e doenças hematológicas submetidos à quimioterapia para transplante de medula óssea, o grau da mucosite bucal com alguns fatores de risco como idade, utilização de fatores de crescimento e regime de tratamento (drogas usadas), por meio da análise de regressão multivariada, concluíram que o único fator de risco independente para a manifestação da mucosite bucal foi o regime de condicionamento para tratamento, principalmente quando o melphalan era utilizado.

De acordo com os protocolos de tratamento da LLA, GBTLI $93^{10}$, GBTLI $99^{11}$, ALL-BFM $95^{51}$ e ALL-BFM02 ${ }^{52}$ as principais drogas quimioterápicas associadas a estomatotoxicidade incluem o metotrexate, a daunorrubicina, o vepesid, a ciclofosfamida, a 6-mercaptopurina e a 6-tioguanina. Estes agentes medicamentosos são utilizados geralmente em conjunto nas diferentes fases do tratamento quimioterápico da $\operatorname{LLA}^{10,11,51,52}$.

No protocolo ALL-BFM 95 ${ }^{51}$, as drogas quimioterápicas utilizadas na fase de indução baseiam-se no uso da prednisona, vincristina, daunorrubicina, asparaginase, ciclofosfamida/mesma, citarabina, 6-mercaptopurina e o metotrexate intratecal (para prevenção da doença no sistema nervoso central, pois a maioria das drogas não atravessa a barreira hemoliquórica) nos grupos de baixo e médio risco (Figura 8,9,10). No GBTLI 93 (Figura 3,4,5) e GBTLI 99 (Figura 6,7) essas mesmas drogas quimioterápicas são também utilizadas com exceção da prednisona que é substituída pela dexametasona e a daunorrubicina que é administrada com menor dosagem.

Dentre estas drogas quimioterápicas usadas no tratamento da LLA, o metotrexate (MTX) é um dos agentes terapêuticos mais eficazes inibindo a proliferação das células malignas atuando como um antagonista do ácido fólico ${ }^{11,61}$. Seu acúmulo 
intracelular e do seu metabólito (MTX-PG) são apontados como importantes determinantes da sobrevida livre de doença em crianças leucêmicas, tratadas inicialmente com MTX ${ }^{11}$.

Os sinais clínicos da intoxicação pelo MTX incluem dentre outros efeitos, a mucosite bucal devido ao seu efeito estomatotóxico direto. É absorvido no trato gastrointestinal e excretado pelos rins, na presença de lesão renal os níveis permanecem elevados, aumentando a toxicidade. São imprescindíveis a hiper-hidratação, assim como, a adequada alcalinização urinária do paciente ${ }^{11}$.

Tendo em vista que na fase de indução dos diferentes protocolos de tratamento da LLA a dose total de metotrexate é maior no protocolo de tratamento ALL-BFM 95 se comparado ao GBTLI 93 e 99, podemos inferir que a mucosite bucal em nossa casuística pode estar refletindo uma maior toxicidade sistêmica do MTX ou mesmo uma maior retenção desta droga no organismo dos pacientes submetidos ao protocolo de tratamento ALL-BFM 95.

Não podemos deixar de ressaltar que o tratamento quimioterápico utilizado no tratamento da LLA se baseia em uma associação de drogas citotóxicas administradas conjuntamente, sendo que muitas destas são freqüentemente relacionadas à ocorrência da mucosite bucal. Dentre estas, a mercaptopurina também possui efeito citotóxico atuando como antagonista da purina e interferindo na incorporação da adenina e guanina aos ácidos nucléicos ${ }^{11}$. Sua toxicidade hematológica associa-se a ocorrência de leucopenia e plaquetopenia, além da mucosite bucal ${ }^{11}$.

Outra droga quimioterápica com ação estomatotóxica é a ciclofosfamida que além de causar profunda mielossupressão está associada com outras intercorrências clínicas como náuseas, vômitos, diarréia, perda do cabelo, dano cardíaco, perda de apetite, esterilidade e mucosite bucal ${ }^{11}$. Além dessas, uma droga de comprovado efeito 
estomatotóxico é a daunorrubicina que atua inibindo o crescimento celular, diminuindo o índice mitótico e causando clinicamente febre, anorexia, vômitos, anemia, leucopenia, plaquetopenia e ulcerações na mucosa bucal ${ }^{11}$.

As dosagens das drogas e a forma de administração são realizadas de forma seqüencial de acordo com o esquema do protocolo de tratamento para LLA a que o paciente é submetido sendo o intervalo entre o final de uma fase e o início da próxima fase variável de acordo com as condições do paciente e o proposto pelo protocolo de tratamento $^{32,34,42,43,51}$.

Para SONIS; FAZIO; FANG. ${ }^{61}$, os efeitos colaterais durante o tratamento da LLA, como por exemplo a ocorrência da mucosite bucal, estão diretamente relacionados com a dose da droga administrada em determinado tempo. Segundo estes autores o intervalo entre a administração da droga é provavelmente mais importante do que a dose total da droga e, portanto, se uma determinada dose pode causar problemas bucais significativos, quando administrada em dose única, pode não causar nenhuma alteração se administrada em doses menores e num período de tempo prolongado. Assim sendo, o risco de desenvolvimento de mucosite bucal é maior com o aumento do número de ciclos quimioterápicos ${ }^{30,40,67}$.

Enfim, cada medicação quimioterápica para LLA exibe alguma forma de comprometimento do paciente oncológico, causando desde doenças com manifestações sistêmicas até alterações teciduais localizadas, como ocorre com a mucosite bucal. A investigação de outras doenças sistêmicas e bucais associadas ou não a mucosite também foi um dos objetivos deste estudo.

Ao analisarmos a Tabela 13 podemos verificar que muitas das intercorrências clínicas estavam associadas diretamente com a terapia imunossupressora utilizada no tratamento da LLA, destacando-se a diabetes pelo Elspar (asparaginase), as cardiopatias 
e a hepatite medicamentosa. Estas alterações são geralmente esperadas sendo destacadas como possíveis intercorrências clínicas nos diferentes protocolos de tratamento da $\operatorname{LLA}^{10,11,51,52}$.

As doenças infecciosas com manifestações sistêmicas como as sinusites, bronquites, as pneumonias, dentre outras, também ocorreram nos pacientes oncológicos pediátricos do Hospital Infantil Darcy Vargas, durante o tratamento da leucemia linfóide aguda, simultaneamente ou não à ocorrência de mucosite bucal (Tabela 13). Devido à terapia imunossupressora, muitas das infecções, citadas acima eram esperadas durante o tratamento da LLA. Porém, estas infecções tornam-se mais graves quando ocorrem simultaneamente a mucosite bucal, pois a perda da integridade epitelial especialmente em pacientes mielossuprimidos, faz com que haja um acentuado aumento no risco de bacteremia e septicemia bem como, no risco de morbidade e/ou óbito ${ }^{18,45,56,58}$.

Especificamente na boca, o herpes labial foi a infecção viral mais freqüente entre os pacientes oncológicos pediátricos com LLA de nosso estudo, manifestando-se em 23 pacientes sendo que 13 destes também apresentaram mucosite bucal (Tabela 13). Outras infecções bucais de origem fúngica como a queilite angular ou bacteriana como a actinomicose também foram registradas (Tabela 13). Estas infecções mesmo localizadas na mucosa bucal são muitas vezes responsáveis pelo total desequilíbrio sistêmico do paciente, interferindo diretamente na qualidade de vida e no prognóstico de cura dos pacientes com LLA $8,9,17,18,31,42,45,56$.

A ocorrência de mucosite bucal com altas doses de quimioterapia administradas em paciente com tumores sólidos ou linfomas também foi correlacionada por ELTING et al. ${ }^{17}$, 2003, salientando que o risco de infecção em pacientes imunossuprimidos foi significativamente mais alto durante os ciclos quimioterápicos com mucosite bucal do que nos ciclos sem mucosite bucal com o mesmo nível e duração da neutropenia e com 
o aumento da gravidade da mucosite bucal. Os autores enfatizaram que os óbitos relacionados com infecção são mais comuns durante ciclos com mucosite bucal e gastrointestinal.

Nota-se ainda, que em nossa amostra, seis pacientes eram portadores da Síndrome de Down e um paciente apresentou Anemia Falciforme (Tabela 13). Esta associação da LLA com algumas síndromes tem sido descrita na literatura ${ }^{26,34,41,60}$. Nessas síndromes estão presentes os denominados sítios frágeis, em alguns cromossomos, os quais representam zonas de instabilidade cromossômica, representando locais de difícil reparo do DNA após a exposição do indivíduo a agentes mutagênicos ambientais ${ }^{34}$.

A análise de nossos resultados confirmou que a mucosite bucal em pacientes oncológicos pediátricos com LLA tratados ou em tratamento no Hospital Infantil Darcy Vargas, em São Paulo, está diretamente correlacionada com o protocolo de tratamento a que foi submetido o paciente e fortemente sugerem uma maior estomatotoxicidade do protocolo ALL-BFM 95. Podemos então concluir que a mucosite bucal deveria ser sistematicamente analisada nos centros especializados no tratamento da LLA que adotam diferentes protocolos de tratamento, visando não somente contribuir com a análise do grau de toxicidade das drogas quimioterápicas, mas principalmente, melhorar a qualidade de vida do paciente com base em condutas terapêuticas e profiláticas mais efetivas na prevenção de sua ocorrência. 
7 CONCLUSÃO 



\section{CONCLUSÃO}

Com base na análise retrospectiva da ocorrência de mucosite bucal nos 169 pacientes oncológicos pediátricos com leucemia linfóide aguda submetidos aos protocolos de tratamento GBTLI 93, GBTLI 99, ALL-BFM 95 e ALL-BFM 02, no Setor de Oncologia Pediátrica do Hospital Infantil Darcy Vargas, em São Paulo verificamos:

- que esta neoplasia maligna foi mais prevalente no gênero masculino e em pacientes com idade inferior ou igual a nove anos;

- uma baixa freqüência de óbitos pela LLA;

- um índice de cura de 50\% nos pacientes submetidos ao protocolo de tratamento GBTLI 93;

- uma freqüência de mucosite bucal em 46\% dos pacientes;

- que não houve correlação estatisticamente significativa entre a ocorrência de mucosite bucal e o gênero $(p=0,08)$, a idade $(p=0,33)$ e a leucometria inicial $(\mathrm{p}=0,34)$;

- que a freqüência de mucosite bucal nos pacientes submetidos ao protocolo de tratamento ALL-BFM de 1995 foi maior e estatisticamente significativa $(\mathrm{p}=0,012)$ quando comparada aos pacientes tratados pelos protocolos GTBLI-93 e GTBLI-99; 
- na análise multivariada e comparativa de todas as variáveis juntas (gênero, idade, leucometria inicial e protocolos de tratamento), o protocolo de tratamento ALL-BFM 95 foi a única variável estatisticamente significativa ( $p=0,009)$ com relação a ocorrência de mucosite bucal;

- uma maior freqüência de mucosite bucal nos pacientes de risco básico de recaída quando analisamos os pacientes submetidos ao protocolo de tratamento GBTLI 93;

- que no protocolo de tratamento da LLA do grupo Berlim-Frankfurt-Munique de 1995, os pacientes de médio risco de recaída foram os que apresentaram mais mucosite bucal;

- que $77,8 \%$ dos pacientes do grupo de alto risco no protocolo de tratamento do Grupo Brasileiro de Tratamento da Leucemia Infantil de 1999, manifestaram a mucosite bucal em algum momento do tratamento quimioterápico;

Nossos resultados confirmaram que a mucosite bucal em pacientes oncológicos pediátricos com LLA está diretamente correlacionada com o protocolo de tratamento a que foi submetido o paciente e fortemente sugerem uma maior estomatotoxicidade do protocolo ALL-BFM 95. Podemos então concluir que a mucosite bucal deveria ser sistematicamente analisada nos centros especializados no tratamento da LLA que adotam diferentes protocolos de tratamento, visando não somente contribuir com a análise do grau de toxicidade das drogas quimioterápicas, mas principalmente, melhorar a qualidade de vida do paciente com base em condutas terapêuticas e profiláticas mais efetivas na prevenção de sua ocorrência. 
REFERÊNCIAS BIBLIOGRÁFICAS 



\section{REFERÊNCIAS BIBLIOGRÁFICAS}

1 AMANTE, C.J. Estudo da relação entre o grau de mucosite da cavidade bucal e os quimioterápicos utilizados para o tratamento das crianças portadoras de leucemia linfoblástica aguda, na faixa etária de 01 a 15 anos. 1995. 63 p. Dissertação (Mestrado em Odontologia) - Universidade de Santa Catarina, Florianópolis, 1995.

2 BAIAN, B.J. Classification of acute leukaemia: the need to incorporate cytogenetic and molecular genetic information. J Clin Pathol, London, v. 51, n. 6, p. 420-423, June 1998.

3 BARASCH, A; PETERSON, D.E. Risk factors for ulcerative oral mucositis in cancer patients: unanswered questions. Oral Oncol, Oxford, v. 39, n. 2, p. 91-100, Feb. 2003.

4 BEHRMAN, R.E.; KLIEGMAN, R.; NELSON, W.E. Acute lymphoblastic leukemia. In: Textbook of pediatrics. 15.ed. Saunders Company: Philadelphia, 1996. Cap. 449, p. 1453-1457.

5 BELLM, L.A. et al. Patient reports of complications of bone marrow transplantation. Support Care Cancer, Alemanha, v. 8, n. 1, p. 33-39, Jan. 2000.

\footnotetext{
* Normas recomendadas para uso no âmbito da Universidade de São Paulo, com base no documento Associação Brasileira de Normas Técnicas - ABNT NBR 6023/ ago. 2002.
} 
6 BIONDI, A. et al. Biological and therapeutic aspects of infant leukemia. Blood, Washington, v. 96, n. 1, p. 420-423, July 2000.

7 BIRON, P. et al. Research controversies in management of oral mucositis. Support Care Cancer, Alemanha, v.6, n.1, p.68-71, Dec. 2000.

8 BLIJLEVENS, N.M.A. Implications of treatment-induced mucosal barrier injury. Curr Opin Oncol, Philadelphia, v. 17, n. 6, p. 605-610, Nov. 2005.

9 BLIJLEVENS N.M.A.; DONNELLY J.P.; DE PAUW B.E. Mucosal barrier injury: biology, pathology, clinical counterparts and consequences of intensive treatment for haematological malignancy: an overview. Bone marrow transplantation, England, v. 25, n. 12, p. 1269-1278, June 2000.

10 BRANDALISE, S.R. et al. Protocolo cooperativo GBTLI LLA-93 para o tratamento da leucemia linfóide aguda na infância. Programa da Sociedade Brasileira de Oncologia Pediátrica e Sociedade Brasileira de Hematologia e Hemoterapia, UNICAMP, Campinas, 1993.

11 BRANDALISE, S.R. et al. Protocolo cooperativo GBTLI LLA-99 para o tratamento da leucemia linfóide aguda na infância. Programa da Sociedade Brasileira de Oncologia Pediátrica e Sociedade Brasileira de Hematologia e Hemoterapia, UNICAMP, São Paulo, 2000.

12 CHESSELLS, J.M. Recent advances in management of acute leukaemia. Arch Dis Child, Inglaterra, v. 82, n. 6, p. 438-442, June 2000.

13 CHO, S.Y.; CHENG, A.C.; CHENG, M.C.K. Oral care for children with leukaemia. Hong Kong Med J, Hong Kong, v. 6, n. 2, p. 203-208, June 2000. 
14 CONDUTAS DO INCA/MS. Leucemias agudas na infância e adolescência. Rev

Bras Cancerol, Rio de Janeiro, v. 47, n. 3, p. 245-254, jul./ago./set. 2001.

15 COSTA, E.M.M. de B. et al. Evaluation of an oral preventive protocol in children with acute lymphoblastic leukemia. Pesqui Odontol Bras, São Paulo, v. 17, n. 2, p. 147-150, abr./jun. 2003.

16 DeANGELO, D.J. The treatment of adolescents and Young adults with acute lymphoblastic leukemia. Hematology Am Soc Hematol Educ Program, Washington, v. 1, p. 123-130, Jan. 2005.

17 ELTING, L. et al. The burdens of cancer therapy: clinical and economic outcomes of chemotherapy-induced mucositis. Cancer, New York, v. 98, n. 7, p. 1531-1539, Oct. 2003.

18 EPSTEIN, J.B.; SCHUBERT, M.M. Oral mucositis in myelossupressive cancer therapy. Oral Surg Oral Med Oral Pathol, St. Louis, v. 88, n. 3, p. 273-276, Sept. 1999.

19 FARIAS, M.G.; CASTRO, S.M. de. Diagnóstico laboratorial das leucemias linfóides agudas. J Bras Patol Med Lab, Rio de Janeiro, v. 40, n. 2, p. 9198, abr. 2004.

20 FELIX, C.A.; LANGE, B.J., CHESSELLS, J.M. Pediatric Acute Lymphoblastic Leukemia: Challenges and Controversies in 2000: Hematology Am Soc Hematol Educ Program, Washington, p. 285-302, 2000.

21 FELIX, C.A.; LANGE, B.J. Leukemia in Infants. Oncologist, Dayton, v. 4, n. 3, p. 225-240, June 1999.

22 GAYNON, P.S.; TRIGG, M.E.; UCKUN, F.M. Childhood acute lymphoblastic leukemia. In: BASTS, R.C. et al. Cancer medicine. 5.ed. BC DECKER: Hamilton, 2000. Cap. 138, p. 2140-2150. 
23 GREAVES, M. Science, medicine and the future-Childhood leukaemia. Br Med J, London, v. 324, n. 7332, p. 283-287, Feb. 2002.

24 GURNEY, J.G. et al. Incidence of cancer in children in the United States: sex-, race-, and 1-year age-specific rates by histologic types. Cancer, New York, v. 75, n. 8, p. 2186-2195, April 1995.

25 GURNEY, J.G. et al. Trends in cancer incidence among children in the U.S. Cancer, New York, v. 78, n. 3, p. 532-541, Aug. 1996.

26 HASTINGS, C. Acute leukemia. In: Hematology/ Oncology Handbook. The Children's Hospital Oakland. 1. ed. St. Louis: Mosby, 2002. Cap. 21, p.161-169.

27 HOSPITAL AC CAMARGO. Departamento de Pediatria. Centro de Tratamento de Pesquisa. Leucemia na infância. São Paulo. Disponível em http://www.hcanc.org.br/outrasinfs/ensaios/leukids.html. Acesso em: 9 fev. 2006.

28 HUBER, M.A; TEREZHALMY, G.T. The medical oncology patient. Quintessence Int, Berlim, v. 36, n. 5, p. 383-401, Feb. 2005.

29 HSU, K. et al. Oral toxity associated with chemotherapy. 2003. UPTODATE 11.2. Disponível em http://www.uptodate.com Acesso em: 30 mar. 2004.

30 KÖSTLER, W.J. et al. Oral mucositis complicating chemotherapy and/or radiotherapy: options for prevention and treatment. CA Cancer J Clin, Hagerstown, v. 51, n. 5, p. 290-315, Sept./Oct. 2001.

31 LALLA, R.V.; PETERSON, D.E. Oral mucositis. Dent Clin North Am, EUA, v. 49, n. 1, p. 167-184, Jan. 2005. 
32 LAKS, D. et al. Avaliação da sobrevida de crianças com leucemia linfocítica aguda tratadas com o protocolo Berlim-Frankfurt-Munique. J Pediatr, Rio de Janeiro, v. 79, n. 2, p. 149-158, Mar./Apr. 2003.

33 LINET, M.S. et al. Residential Exposure to Magnetic Fields and Acute Lymphoblastic Leukemia in Children. N Engl J Med, Massachusetts, v. 337, n. 1, p. 1-7, July 1997.

34 LORENZI, T.F. Patologia dos leucócitos. In: Manual de Hematologia, propedêutica e clínica. 2.ed. Medsi: Rio de Janeiro, 1999. Cap. 4, p.327517.

35 LUBIN, J.H. et al. Case-control study of childhood acute lymphoblastic leukemia and residential radon exposure. J National Cancer Institute, local, v. 90, n. 4, p. 1-7, Feb. 1998.

36 MAEDA, M. et al. Clinical aspects of infant leukemia-experiences of a single institution of Japan: high level of serum immunoglobulin in infant leukemia. J Nippon Med Sch, Tokio, v. 72, n. 6, p. 355-363, Dec. 2005.

37 MAEDA, Y.C. Manifestações bucais da leukemia e do tratamento antineoplásico. $\quad$ 1998. $51 \quad$ p. Monografia (Especialização em Odontopediatria) - Faculdade de Odontologia de Piracicaba, Universidade Estadual de Campinas, Piracicaba, 1998.

38 McKenNA, S.J. Leukemia. Oral Surg Oral Med Oral Pathol Oral Radiol Endod, St. Louis, v. 89, n. 2, p. 137-9, Feb. 2000.

39 MINISTÉRIO DA SAÚDE. INSTITUTO NACIONAL DE CÂNCER. COORDENAÇÃO DE PROGRAMAS DE CONTROLE DO CÂNCER. Problema do Câncer no Brasil Epidemiologia dos tumores da criança e do adolescente. Disponível em http://www.inca.org.br Acesso em 8 dez. 2003. 
40 NAIDU, M.U.R. et al. Chemotherapy-induced and/or radiation therapy-induced oral mucositis-complicating the treatment of cancer. Neoplasia, Canadá, v. 6, n. 5, p. 423-431, Sept./Oct. 2004.

41 NEVILLE, B.W. et al. Distúrbios Hematológicos. In: Patologia OralMaxilofacial. 2. ed. Guanabara-Koogan: Rio de Janeiro, 2004. Cap. 13, p.477-510.

42 OLIVEIRA, B.M.; DINIZ, M.S.; VIANA, M.B. Leucemias agudas na infância. Rev Assoc Med Minas Gerais, Belo Horizonte, v. 14, p. 33-39, 2004. Suplemento 1.

43 PEDROSA, F.; LINS, M. Leucemia linfóide aguda: uma doença curável. Rev Bras Mater Infant, Recife, v. 2, n. 1, p. 63-68, jan./abr. 2002.

44 PETERSON, D.E. Research advances in oral mucositis apud KÖSTLER, W.J. et al. Oral mucositis complicating chemotherapy and/or radiotherapy: options for prevention and treatment. CA Cancer J Clin, Hagerstown, v. 51, n. 5, p. 290-315, Sept./Oct. 2001. p. 292.

45 PICO, J.L.; AVILA-GARAVITO, A.; NACCACHE, P. Mucositis: Its occurrence, consequences, and treatment in the oncology setting. Oncologist, Dayton, v. 3, n. 6, p. 446-451, Dec. 1998.

46 PUI, C.H. Childhood leukemias. N Engl J Med, Massachusetts, v. 332, n. 24, p. 1695-1630, June 1995.

47 PUI, C.H.; EVANS, W.E. Acute lymphoblastic leukemia. N Engl J Med, Massachusetts, v. 339, n. 9, p. 605-615, Ago. 1998.

48 PUI, C.H.; EVANS, W.E. Drug therapy: treatment of acute lymphoblastic leukemia. N Engl J Med, Massachusetts, v. 354, n. 2, p. 166-178, Jan. 2006. 
49 PUI, C.H. et al. Childhood acute lymphoblastic leukemia. Rev Clin Exp Hematol, Itália, v. 6, n. 2, p. 161-180, June 2002.

50 RIBEIRO, R.C.; PUI, C.H. Saving the children-improving childhood câncer treatment in developing countries. N Engl J Med, Massachusetts, v. 352, n. 21, p. 2158-2160, May 2005.

51 RIEHM, H. et al. Protocolo terapêutico multicêntrico ALL-BFM 95 para tratamento de crianças e adolescentes com leucemia linfóide aguda. BerlimFrankfurt-Munique, Hannover, [s.n.], 1995. Tradução Lieselotte Laun.

52 RIEHM, H. et al. A randomized trial of the ALL IC-BFM 2002 for the management of childhood acute lymphoblastic leukemia. BerlimFrankfurt-Munique, Hannover, [s.n.], 2002.

53 SANDOVAL, R.L. et al. Management of chemo and radiotherapy induced oral mucositis with low-energy laser: initial results of A.C. Camargo Hospital. J appl oral sci, Bauru, v. 11, n. 4, p. 337-341, 2003.

54 SANTOS, V.I.; ANBINDER, A.L.; CAVALCANTE, A.S.R. Leucemia no paciente pediátrico: atuação odontológica. Cienc odontol bras, São José dos Campos, v. 6, n. 2, p. 49-57, Abr./jun. 2003.

55 SCULLY, C.; SONIS, S. Mucosal diseases series, Oral mucositis. Oral Dis, Denmark, v. 12, n. 3, p. 229-241, May 2006.

56 SONIS, S.T. Mucositis as a biological process: a new hypothesis for the development of chemotherapy-induced stomatotoxicity. Oral Oncol, Oxford, v. 34, n. 1, p. 39-43, Jan. 1998.

57 SONIS, S.T. Oral complications. In: BAST, R.C. et al. Cancer medicine. 5.ed. BC DECKER: Hamilton, 2000. Cap. 153, p. 2371-2379. 
58 SONIS, S.T. The pathobiology of mucositis. Nat Rev Cancer, London, v. 4, n. 4, p. 277-284, Apr. 2004.

59 SONIS, S.T. et al. Perspectives on cancer therapy-induced mucosal injury. Cancer, New York, v. 100, n. 9, p. 1995-2025, May 2004. Supplement 1.SONIS, S.T; FAZIO, R.C.; FANG, L. Doenças malignas do sangue. In: Princípios e Prática de Medicina Oral. 2.ed. Rio de janeiro: Guanabara Koogan, 1996. Cap. 27, p. 225-235. SONIS, S.T; FAZIO, R.C.; FANG, L. Complicações bucais da quimioterapia da câncer. In:

Princípios e Prática de Medicina Oral. 2.ed. Rio de janeiro: Guanabara Koogan, 1996. Cap. 42, p. 358-383.SONIS, S.T.; SONIS, A.L.; LIEBERMAN, A. Oral complications in patients receiving treatment for malignancies other than of the head and neck. J Am Dent Assoc, EUA, v. 97, n. 3, p. 468-472, Sept. 1978.SWENSEN, A.R. et al. The age peak in childhood acute lymphoblastic leukemia. Cancer, New York, v. 79, n. 10, p. 2045-2051, May 1997.TORRES-PEREIRA, C.C. Análise dos fatores de risco para o desenvolvimento de mucosite oral em pacientes submetidos ao transplante de medula óssea. 2002. 178 p. Tese (Doutorado em Odontologia) - Pontifícia Universidade Católica do Rio Grande do Sul, Porto Alegre, 2002.

65 VOKURKA, S. et al. Higher incidence of chemotherapy induced oral mucositis in females: a supplement of multivariate analysis to a randomized multicentre study. Support Care Cancer, Alemanha, v. 14, n. 9, p. 974-976, Sept. 2006. 
66 WARDLEY, A.M. et al. Prospective evaluation of oral mucositis in patients receiving myeloablative conditioning regimens and haemopoietic progenitor rescue. British J Haematology, Inglaterra,v. 110, n. 2, p. 292-299, Aug. 2000.

67 WOO, S.B et al. A longitudinal study of oral ulcerative mucositis in bone marrow transplant recipients. Cancer, New York, v. 72, n. 5, p. 1612-7, Sept. 1993. 


\section{ABSTRACT}





\section{RISK FACTORS TO ORAL MUCOSITIS IN PATIENTS WITH ACUTE LIMPHOBLASTIC LEUKEMIA SUBMITTED TO DIFFERENT TREATMENT PROTOCOLS}

Oral mucositis is one of the main complications secondary to antineoplastic treatment in patients with acute lymphoblastic leukemia (ALL). The risk factors for its occurrence include age, gender and initial leukocyte count, besides chemotherapeutic drugs with known stomatotoxic action. This study investigated the prevalence and risk factors to oral mucositis in patients with ALL submitted to different chemotherapeutic treatment protocols. A total of 169 clinical records of pediatric oncology patients submitted to different treatment protocols for ALL at the Pediatric Oncology Sector of the Child Hospital Darcy Vargas, in the city of São Paulo, in the period 1994 to 2005 were retrospectively evaluated. Demographic (age and gender) and clinical data (initial leukocyte count, treatment protocol adopted, evolution, occurrence of mucositis and other oral lesions) were recorded. The association of oral mucositis with the clinical and demographic variables was assessed by the chi-square test and multivariate logistic regression analysis. The results demonstrated occurrence of oral mucositis in $46 \%$ of pediatric oncology patients with ALL, without statistically significant correlation between its occurrence and gender $(p=0.08)$, age $(p=0.33)$ and initial leukocyte count $(\mathrm{p}=0.34)$. Multivariate analysis revealed that the Berlin-Frankfurt-Munich protocol of 1995 (ALL-BFM 95) was the most significant factor $(\mathrm{p}=0.009)$ to the occurrence of oral mucositis according to the variables evaluated in this study. These results strongly suggest the greater stomatotoxic effect of the ALL-BFM 95 protocol, as demonstrated by the higher frequency of oral mucositis in pediatric oncology patients with ALL. Thus, it may be concluded that oral mucositis should be systematically analyzed in centers specialized in the treatment of ALL adopting different treatment protocols, with a view to contribute to analysis of the degree of toxicity of chemotherapeutic drugs and mainly to improve the quality of life of patients on the basis of more effective therapeutic and prophylactic approaches for prevention of its occurrence.

Keywords: Mucositis. Chemotherapy. Children. Acute lymphoblastic leukemia. 